(C) 2014. This manuscript version is made available under the CC-BY-NC-ND 4.0 license http://creativecommons.org/licenses/by-nc-nd/4.0/

\title{
A Model for the Transient Performance Simulation of Solar Cavity Receivers
}

\author{
Javier Samanes, Javier Garcia-Barberena \\ National Renewable Energy Center (CENER), Solar Thermal Energy Department \\ Address: c/ Ciudad de la Innovación, 7. Sarriguren (Navarra), Spain \\ E-mail: samanes.javier@gmail.com
}

\begin{abstract}
In this paper, a detailed model for the transient simulation of solar cavity receivers for concentrating solar power plants is presented. The proposed model aims to consider all the major phenomena influencing the performance of a cavity receiver, including radiation, convection and conduction heat transfer mechanisms. For the radiation heat exchange within the cavity, the radiosity method is implemented, where the view factor calculation for all the active and passive surfaces is performed by a ray tracing algorithm programmed in a free software environment for statistical computing, namely R. A one-dimensional modeling approach is used for the tubes constituting the receiver active panels, through which the heat transfer fluid (HTF) is pumped. The governing partial differential equations are solved numerically by applying the finite volume method. Convective heat losses are modeled through different correlations for natural and forced convection heat losses from the specific literature. Once the thermal behavior has been characterized, the geometry of the model is later fixed to check the consistency of the model and to study its dynamic characteristics. A specific 51.6 MWth, PS10 like receiver is used in this paper, although the implemented model has the flexibility to allow a variable number of panels and geometric configurations. At last, an adaptive neural controller, designed and trained offline, controls the outlet temperature of the molten salts to the desired operating value. Results for transient simulations are shown in the paper, demonstrating the plausibility of the estimations obtained with the developed model. The proposed model has been implemented in the Modelica Language and based on the Modelica Standard Library (MSL) modeling approach.
\end{abstract}

Keywords: Concentrated Solar Power (CSP) tower cavity receiver, transient performance simulation, adaptive PI neural controller, Modelica. 


\section{NOMENCLATURE}

\begin{tabular}{|c|c|c|}
\hline$A$ & Area & $\mathrm{m}^{2}$ \\
\hline $\begin{array}{l}a \\
a m b\end{array}$ & $\begin{array}{l}\text { Entering the control volume } \\
\text { ambient }\end{array}$ & \\
\hline $\mathrm{b}$ & Going out of the control volume & \\
\hline C & Heat capacity & $\mathrm{J} / \mathrm{K}$ \\
\hline$D$ & Diameter & $\mathrm{m}$ \\
\hline DNI & Direct normal irradiance & $\mathrm{W} / \mathrm{m}^{2}$ \\
\hline$e_{\text {insu }}$ & Width of the insulation surfaces & $\mathrm{m}$ \\
\hline$e_{\text {pipe }}$ & Pipe thickness & $\mathrm{m}$ \\
\hline$E_{b}$ & Black body emissive power & $\mathrm{W} / \mathrm{m}^{2}$ \\
\hline$f$ & Friction factor & \\
\hline$F_{f}$ & Friction force acting on the fluid & $\mathrm{N}$ \\
\hline$F_{g}$ & Gravitational force acting on the fluid & $\mathrm{N}$ \\
\hline$F_{i-j}$ & View factor from surface $i$ to surface $j$ & \\
\hline$F_{p}$ & Pressure force acting on the fluid & $\mathrm{N}$ \\
\hline G & Irradiance & $\mathrm{W} / \mathrm{m}^{2}$ \\
\hline$G r$ & Grashof number & \\
\hline$h$ & Heat transfer coefficient & $\mathrm{W} / \mathrm{m}^{2} \mathrm{~K}$ \\
\hline$h$ & Specific enthalpy & $\mathrm{J} / \mathrm{Kg}$ \\
\hline$H_{c}$ & Receiver height & $\mathrm{m}$ \\
\hline$I$ & Concentrated solar radiation by surface area & $\mathrm{W} / \mathrm{m}^{2}$ \\
\hline $\mathrm{i}$ & Dicretized element number i & \\
\hline$I_{\text {diffuse horizontal }}$ & Diffuse horizontal irradiance & $\mathrm{W} / \mathrm{m}^{2}$ \\
\hline Iglobal horizontal & the global horizontal irradiance & $\mathrm{W} / \mathrm{m}^{2}$ \\
\hline$J$ & Radiosity & $\mathrm{W} / \mathrm{m}^{2}$ \\
\hline$k$ & Thermal conductivity & $\mathrm{W} / \mathrm{m} \cdot \mathrm{K}$ \\
\hline$L$ & Tube length & $\mathrm{m}$ \\
\hline$L_{c}$ & Characteristic length & $\mathrm{m}$ \\
\hline$m$ & Mass & $\mathrm{Kg}$ \\
\hline$\dot{m}$ & Mass Flow rate & $\mathrm{Kg} / \mathrm{s}$ \\
\hline$n_{\text {pan }}$ & Number of active panels & $\mathrm{m}$ \\
\hline$n_{\text {tubes }}$ & Number of tubes inside each panel & $\mathrm{m}$ \\
\hline$N u$ & Nusselt number & \\
\hline $\operatorname{Pr}$ & Prandtl number & \\
\hline$\dot{Q}$ & Heat flow rate & $\mathrm{W}$ \\
\hline$R$ & Thermal resistance & $\mathrm{W} / \mathrm{K}$ \\
\hline$r$ & Pipe radius & $\mathrm{m}$ \\
\hline$R_{c}$ & Cavity inner radius & $\mathrm{m}$ \\
\hline$R e$ & Reynolds number & \\
\hline s & surface & \\
\hline$T$ & Temperature & $\mathrm{K}$ \\
\hline$U$ & Internal energy & $\mathrm{J}$ \\
\hline$u$ & Specific internal energy & $\mathrm{J} / \mathrm{Kg}$ \\
\hline$V$ & Volume & $\mathrm{m}^{3}$ \\
\hline$v$ & Wind velocity & $\mathrm{m} / \mathrm{s}$ \\
\hline$v_{b}$ & Buoyant velocity & $\mathrm{m} / \mathrm{s}$ \\
\hline$v_{c}$ & Velocity of the air inside the cavity & $\mathrm{m} / \mathrm{s}$ \\
\hline$w_{s l}$ & Width of the side lips & $\mathrm{m}$ \\
\hline$w_{u l}$ & Width of the upper lip & $\mathrm{m}$ \\
\hline$\dot{W}$ & Work flow rate & $\mathrm{W}$ \\
\hline $\mathrm{w}$ & wall & \\
\hline$\alpha_{\text {surface }}$ & Absorptivity of the surface & \\
\hline$\delta$ & Operating point, Eq. (36) & \\
\hline$\varepsilon$ & Emissivity & \\
\hline$\eta$ & Effciency & \\
\hline$\theta$ & Angle covered & rad \\
\hline$\theta_{\text {zenith }}$ & Sun zenith angle & $\mathrm{rad}$ \\
\hline$\rho$ & Density & $\mathrm{Kg} / \mathrm{m}^{3}$ \\
\hline$\rho$ & Reflectivity & \\
\hline
\end{tabular}




\section{Introduction}

Solar thermal power technology uses the direct normal irradiance (DNI) incident on the earth's surface, concentrating and collecting it in a specific system, to heat a working fluid. The working fluid is then expanded in a turbine in order to generate electricity. The solar thermal energy can also be stored in the form of sensible or latent heat for its later usage. Also thermochemical heat storage is possible. Among the CSP technologies, central receiver or power tower plants represent a promising technology. One of the reasons for this is the fact that they provide high area concentration ratios, which means that these plants can be efficiently run at high temperatures maximizing the conversion efficiency of the power cycle. Since the first commercial solar thermal power tower plant, PS10 in Sanlucar La Mayor, Spain, was connected to the grid in 2007, the interest in this technology has largely increased. Currently, solar tower technologies account for $457 \mathrm{MW}$ operating worldwide, $210 \mathrm{MW}$ under construction and about $6000 \mathrm{MW}$ planned [1].

In CSP technologies, as in any other technology, any design needs to be tested through simulation in order to be validated prior to its real construction. This is the reason why there is a latent need to develop accurate models for solar thermal power tower plants and, particularly, there is a great interest in developing simulation models for cavity receivers, which have been suggested to reach larger efficiencies than external receivers [2]. For modeling these receivers, one of the most critical part is the accurate modeling of the heat losses, which will finally determine its efficiency, even though other critical aspects should be taken into account i.e. material stress, optical, fatigue...

However, modeling the heat losses of a cavity receiver can be a challenge considering the complexity of the heat transfer mechanisms involved and the infinite number of possible geometric configurations. Basically, thermal heat losses can be divided into conduction losses, radiation losses and convection losses. Conduction losses are related to the heat flow rate flowing through the insulation layers to the ambient, finally lost by convection and radiation. Radiation heat losses, account for both the solar radiation and thermal radiation leaving the cavity receiver through the aperture. Finally, convection heat losses are defined as the heat flow rate flowing out of the cavity aperture due to natural or forced convective transfer.

Two main trends can be found in the state-of-the-art commercial solar power tower plants regarding the heat transfer fluid applied: molten salts and water/steam. The current solution to store large quantities of thermal energy is a two-tank system using molten salts. That is, if the heat transfer fluid is water/steam a heat exchanger is required between the storage and the receiver. For this reason, a commercial solution in CSP tower technology is using molten salts as the heat transfer fluid. In this plant configuration the fluid is pumped to the receiver at the top of the tower where it is heated and then used to store the thermal energy in a two-tank system. In the case of using Solar Salt ( $60 \% \mathrm{NaNO}_{3}$ and $40 \% \mathrm{KNO}_{3}$ by weight), the working temperature of the molten salts cannot exceed $600{ }^{\circ} \mathrm{C}$, because of the salts' chemical decomposition and the rapidly increasing corrosion rates of piping materials at higher temperatures. This non-eutectic nitrate salt mixture has its solidus temperature at $223^{\circ} \mathrm{C}$ and its liquidus temperature at $238^{\circ} \mathrm{C}$, detailed information on molten salts' properties can be found in [3] and [4]. The typical outlet temperature of this fluid is around $565^{\circ} \mathrm{C}$.

The raising interest in CSP tower technologies and more precisely, in cavity receivers, has highly reactivated the interest in modeling and simulating these systems, an interest that was born in the early 80 's. This work is focused on the transient performance simulation of cavity receivers used in CSP tower plants. It proposes an object-oriented, Modelica-based, distributed parameter model, suitable for system performance simulations that allow the testing, evaluating and improving of operating and control strategies to meet the operation requirements by adjusting the mass flow rate. By making some simplifications, a fast and still accurate model is developed, able to perform long simulations over a whole day, week or year.

To build the model presented in this paper, a wide literature survey was needed to understand the different approaches to the problem. Basically, already proposed solar cavity receiver models can be subdivided into two groups, (i) three dimensional numerical models with high spatial resolution, based on detailed 
Computational Fluid Dynamics (CFD) analyses, and (ii) numerical as well as analytical models of lower spatial resolution.

CFD models analyze the influence of the geometry in the heat loss process with a very accurate and realistic approach. The cavity's inner volume is intensively divided into nodes, where the flow patterns created by wind effects and buoyant forces are studied. CFD analysis of cavity receivers can be found in different works, such as in [5], but the computational cost of these studies is so high that it is not the correct approach for the modeling purposes of the present paper.

Due to the relatively high computational effort, models of much lower spatial resolution are applied for transient response simulations that are required for the evaluation of receiver operation and control strategies. Thermal heat losses determine the performance of a solar receiver, determining the heat flow rate lost to the ambient and thus the heat flow rate absorbed by the heat transfer fluid should be the main goal of the transient simulation. Although modeling conduction heat losses and radiation heat losses is quite straightforward by making some simplifications, convective heat losses present a greater difficulty. The heat transfer coefficients needed to calculate the heat flow rate lost by convection are most often based on empirical correlations. These correlations need to be adjusted by performing experiments under certain conditions and are usually only valid for specific geometries.

For the modeling purposes of the present work, the first step has been conducting an extensive survey of the specific literature related to modeling convective heat losses. Convective heat losses are most often calculated by adding the results provided by forced convection correlations and natural convection correlations. While there is a tendency to use the forced convection correlation derived by Siebers and Kraabel [6] there is not a general agreement in what correlation should be used to model natural convection heat losses. Thus, the main publications concerning natural convection heat losses have been studied. Clausing [7] provided a correlation for the Nusselt number that was able to provide the appropriate value for each surface by taking into account the surface orientation, the surface temperature and the ambient temperature. Siebers and Kraabel [6], determined a global heat transfer coefficient for the cavity receiver as a function of the Grashoff number, the cavity average temperature and the ambient temperature, this coefficient is weighted by the areas of the cavity to calculate the total heat transfer coefficient. Four years after his previous analysis of a cavity receiver, Clausing, Waldvogel et al. [8] calculated a global heat transfer coefficient for the cavity receiver in terms of three parameters, the first one representing the natural convection correlation from the internal cavity surfaces to the surroundings for constant properties, the second one is the quantity which accounts for variable property influences because of the difference of wall and ambient temperature and the last parameter accounting for the effects that occur when the temperature of the air inside the cavity is significantly different than the ambient temperature. In the study of Leibfried and Ortjohann [9] the flow configuration in a hemispherical cavity receiver is studied, determining a global Nusselt correlation accounting for the ambient temperature, the cavity average temperature and the orientation of the cavity. In the last years Paintoosurikarn and Lovegroove [10] developed a Nusselt correlation depending on the Grashoff and the Prandtl number for solar dish cavity receivers, the characteristic length is calculated as a function of the cavity geometry. Even though it was developed for solar dish cavity receivers, it was also tested in large cavities, providing accurate results. For further information concerning the correlations presented above see [11] and [2][2].

A transient model of a cavity receiver is not able to dispatch usable thermal energy unless a control strategy is programmed. Camacho et al. [12][13] presented a review of the different basic and advanced control strategies for distributed solar collectors. Even though the dynamics of tower receivers are different than in distributed collectors, the same control strategies can be implemented. The controller developed in the present paper is inspired by Pickhardt [41] and Henriques et al. [42] who developed, respectively, an adaptive control of a solar power plant using a multi model and a scheduling of PID controllers by means of a neural network applied to a solar power plant. 
The intention of this work is to build upon already proposed standard modeling methodologies and to discuss a flexible and intuitive approach for the transient modeling of solar cavity receivers. This model is then used in order to study the transient behavior of a tower cavity receiver and design a control strategy that is able to fix the temperature at the outlet of the pipes by controlling the mass flow rate. A proportional integral controller (PI), is adapted for five operation points where the receiver is linearized. Two neural networks adapt the parameters of the controller for values between the operation points. The performance of the controlled system is studied through a simulation over 6 days, proving robustness to perturbations.

\section{Receiver Geometry}

In this work a cavity receiver model is implemented, allowing a large flexibility in its geometry. Despite this flexibility, a predefined configuration is chosen among the infinite number of geometric possibilities. Figure 1 represents the predefined geometry of the receiver, constituted by a variable number of panels, which contain a large variable number of parallel steel tubes, uniformly arranged inside the cavity. As can be seen in Figure 2, the panels where the solar radiation is focused are protected from the ambient conditions by a semi-cylindrical concrete insulation layer; this wall covers the back part of the active surfaces. The cavity incorporates also the ceiling and the floor as well as three front lips that define the aperture area. In this way, the cavity receiver protects the active surfaces from losing great amounts of energy to the ambient.

As it can be seen in Figure 1 the geometry of the cavity receiver is inspired by the PS10 cavity receiver [14].

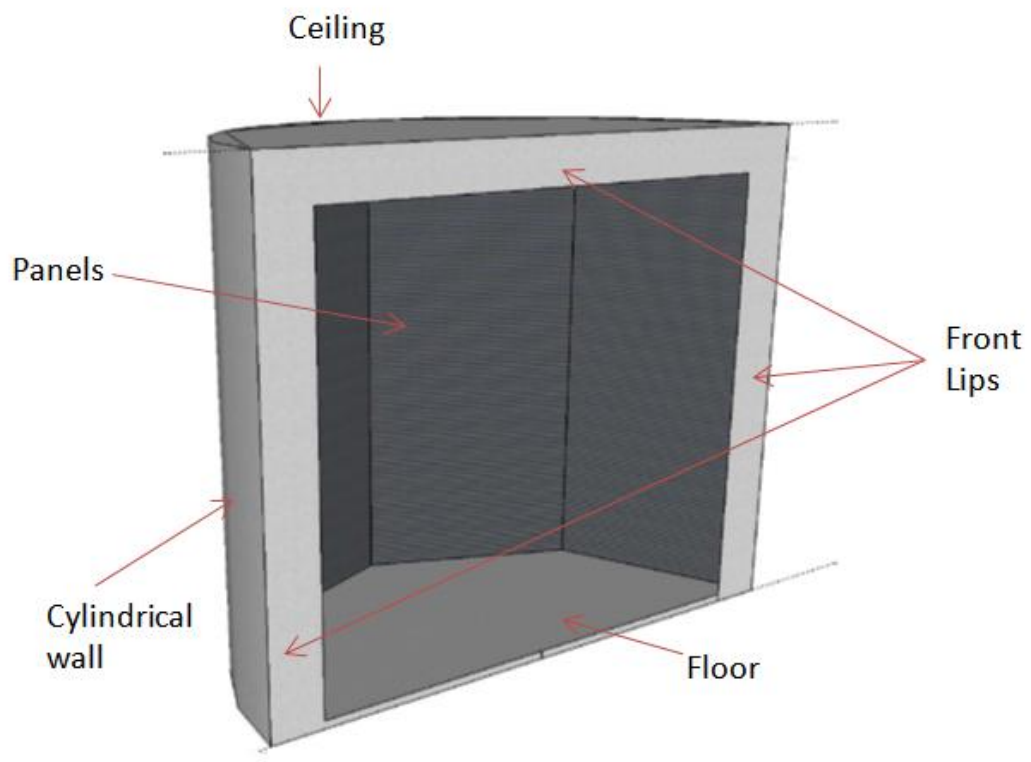

Figure 1. PS10-like cavity receiver.

Eight parameters are taken as inputs by the model to completely define its geometry. 
- $R_{c}$ : cavity radius, which defines the inner radius of the cavity, fixed at the center of the aperture

- $H_{c}$ : receiver height, which is the internal height of the cavity and thus the height of the active surfaces

- $e_{\text {insu }}$ : width of the insulation surfaces, this parameter is the same for all the passive surfaces already mentioned

- $\quad w_{s l}$ and $w_{u l}$ : width of the side lips and upper lip respectively

- $n_{\text {tubes }}:$ number of tubes inside each panel

- $n_{\text {panels: }}$ number of active panels

- $\quad e_{\text {pipe: }}$ pipe wall thickness

Figure 2 shows a schematic of the receiver, representing the parameters already explained.
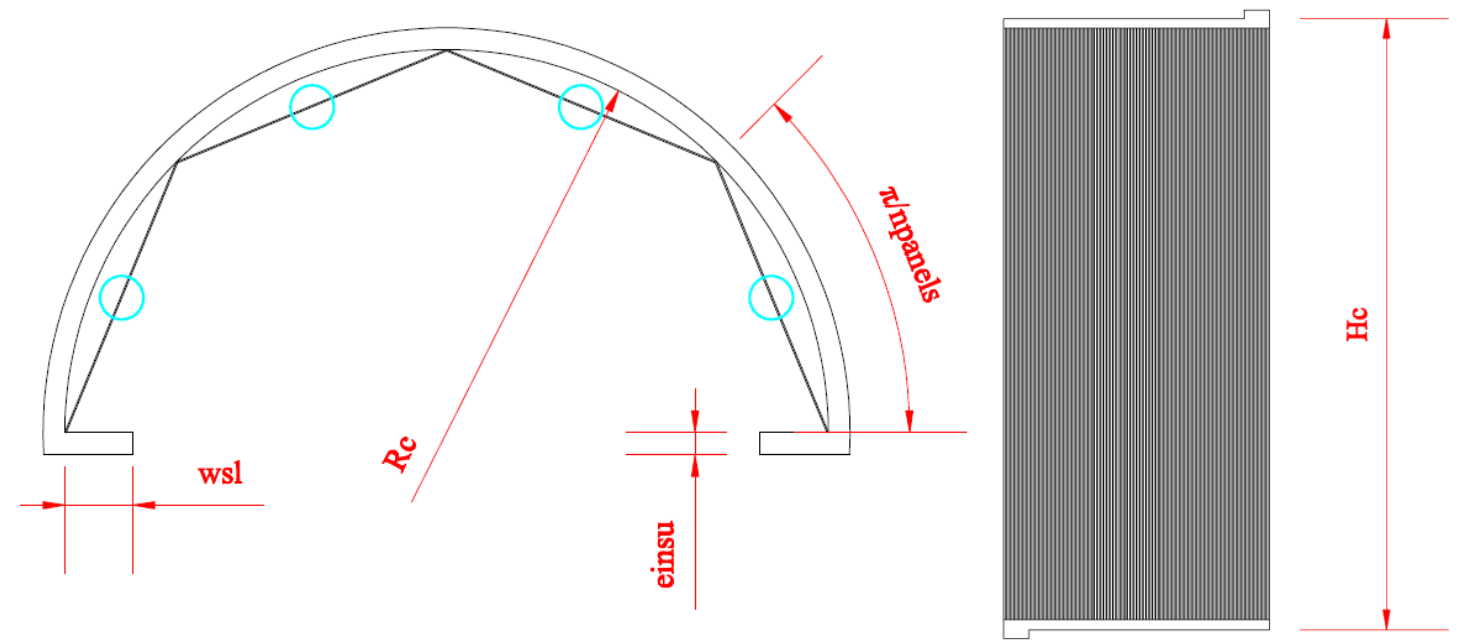

Figure 2. Schematic of the receiver.

Once the parameters have been defined, the model internally calculates the surface areas.

\section{Methodology and Modeling Approach}

The model presented in this work is a transient model for solar cavity receivers based on the Modelica language. Modelica is an object-oriented multi-purpose physical system modeling language and has been developed in an international effort in order to unify already existing similar modeling approaches and enable developed models and model libraries to be easily exchanged. The concept is based on non-causal models featuring true ordinary differential and algebraic equations, i.e. differential-algebraic equation (DAE) systems [15]. The possibility of multiple inheritances and the re-declaration feature leads to a clear model structure, avoids multiple definitions of frequently used code and offers a large flexibility in the models. The code syntax and application guidelines are defined in the regularly updated Modelica language specification [16]. Instead of developing a specific solving algorithm for each modeling task, the Modelica tool reads the developed Modelica code, performs symbolic manipulations of equations and translates the Modelica model into numerical simulation code, using state-of-the-art solving algorithms developed for general application. The use of Modelica clearly decouples the modeler from the equation system solving. Developed models and model libraries are exchangeable, i.e. can be read and simulated using different Modelica environments. Today, commercial, as well as open-source Modelica environments are available [17][18].

In order to achieve a clear and flexible model structure that is not limited to the single cavity receiver configuration, the final cavity receiver model will be composed of several generic sub-models. The combination of these sub-models in a single one allows calculating the thermal performance of cavity 
receivers by computing the individual heat losses of every surface and is intended to perform long term simulations of different cavity receivers. By the reusability and replaceability of the Modelica language, the implemented model admits different geometries, materials and heat transfer fluids, although this flexibility implies, obviously, a limitation on the accuracy. Each of the sub-models will be explained in the following.

\subsection{Modeling the Panels of the Receiver}

As commented in Section 2, the panels are formed by a large number of thin tubes through which the heat transfer fluid flows. In transient simulation, speed is a key factor; this is the reason why only a representative tube is simulated. By studying the dynamic characteristics of 1 equivalent tube per panel instead of analyzing each tube, the computational cost is drastically reduced.

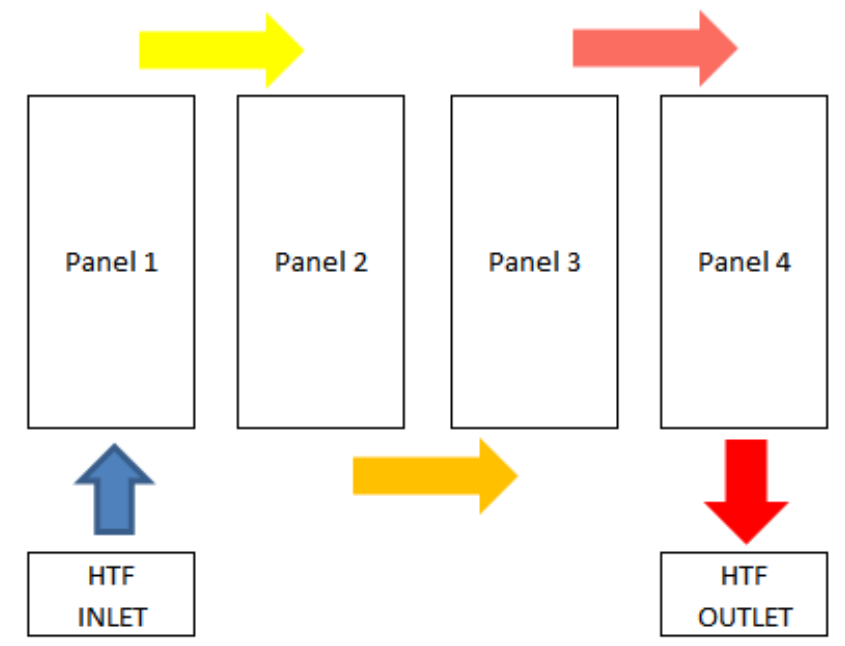

Figure 3. HTF flow configuration through the panels.

Each tube is modeled by smaller Modelica classes, which represent different aspects of its behavior. In such a way a complete representation of the tube is formed by connecting the fluid flow model by the internal forced convection model to the steel pipe model and furthermore connecting the pipe model to the heat loss models. The fluid flow model is complemented with the pressure drop model, and makes use of the HTF model that contains the properties of the molten salts.

\subsubsection{1-D Fluid Flow Configuration through the Panels}

The fluid ducts are modeled according to the MSL's concept (the MSL is the Modelica Standard Library, an open source library). Since this one-dimensional fluid flow modeling approach is a key part of the model, it will be explained in the following. However, the full transient implementation will not be used, since a simplified version will be more efficient for this study's intentions. Therefore, all simplifications will be explained and justified.

The MSL offers a rigorous implementation of a one-dimensional fluid flow model according to the finite volume method (FVM) [19]. The total flow volume is discretized in $n$ finite control volumes along the flow direction. In order to avoid a multiple definition of the basic mass and energy balances, the one-dimensional flow model extends from the MSL base class "partial distributed volume". This generic base class defines the mass and energy balances in terms of net mass flow, net enthalpy flow, net heat flow $\dot{Q}_{\text {net }}$ and net work flow $\dot{W}_{\text {net }}$, for each control volume $i$ (Figure 4). This can be written as follows: 


$$
\begin{gathered}
m_{i}=V_{i} \cdot \rho_{i} \\
\frac{d m_{i}}{d t}=\dot{m}_{a, i}-\dot{m}_{b, i} \\
U_{i}=m_{i} \cdot u_{i} \\
\frac{d U_{i}}{d t}=\dot{m}_{a, i} \cdot h_{a, i}-\dot{m}_{b, i} \cdot h_{b, i}+\dot{Q}_{n e t, i}+\dot{W}_{n e t, i}
\end{gathered}
$$

Where:

- $\dot{W}_{\text {net, } i}$ is set to zero

- $m_{i}$ is the mass of the fluid inside the control volume $i$

- $\quad V_{i}$ is the volume of the control volume $i$

- $\quad \rho_{i}$ is the density of the fluid inside the control volume $i$

- $\dot{m}_{a, i}$ and $\dot{m}_{b, i}$ are, respectively, the mass flow rates entering and exiting the control volume $i$

- $U_{i}$ and $u_{i}$ are the internal energy and the specific internal energy

- $h_{a, i}$ and $h_{b, i}$ are, respectively, the specific enthalpy values of the mass flow entering and exiting the control volume.

Having formulated the general mass and energy balances, the momentum balances have to be defined as well, in order to provide the missing relationship between the pressure states and the mass flow rates between the neighboring volumes. This is implemented according to the staggered grid approach [20], hence the grid of the momentum balances and the grid of the finite control volumes are displaced relative to each other (Figure 4), i.e. resulting in an alternating concept of momentum balances (shaded squares) and control volumes (black solid lines). The shaded dots in the centers of the control volumes represent the thermodynamic state vectors, either pressure and specific enthalpy, or pressure and temperature, depending on the selected states.

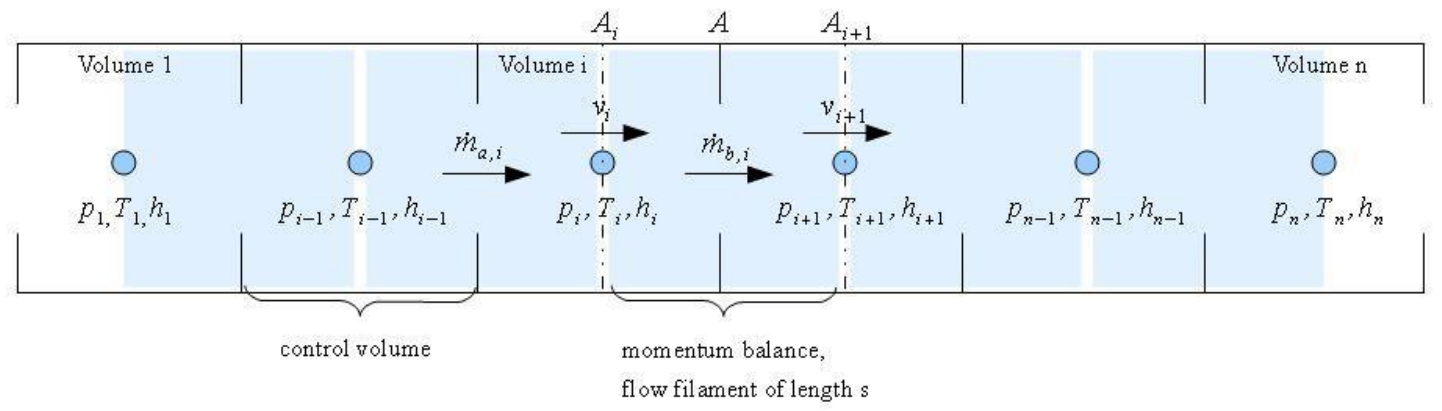

Figure 4. $\quad$ Finite volume discretization scheme according to the staggered grid approach [20]

The implementation of the momentum balance is accomplished in the base class "partial distributed flow", and can be written as follows, considering the discrete flow filament of length " $s$ ".

$$
\frac{d}{d t}\left(\dot{m}_{b, i} \cdot s\right)=v_{i}^{2} \cdot \rho_{i} \cdot A_{i}-v_{i+1}^{2} \cdot \rho_{i+1} \cdot A_{i+1}-F_{p}-F_{f}-F_{g}
$$

Where $A_{i}$ is the transversal area of volume $\mathrm{i}$. The momentum balance has been reduced to its steady-state formulation, by furthermore neglecting differences in the velocity, $v_{i}$, and the influence of the gravitational force. These assumptions lead to the equation $F_{p}=-F_{f}$, which states that the pressure difference between two neighboring control volumes is the pressure drop due to friction, ignoring pressure wave propagations within the ducts. 


\subsubsection{Pipe Models}

The representative tube modeled for each panel is a thin steel tube. As explained in Section 3.1.1, the pipe flow itself is modeled according to the finite volume method formulating the momentum balance in steady state. The pipe's steel wall is modeled as a cylindrical one-dimensional conduction model, having one or several temperature nodes in radial direction. The wall's capacitance is assumed to be lumped together at the single temperature nodes. Heat conduction in flow direction is neglected. However, the cylindrical conduction model is divided into discrete sections in flow direction (longitudinal direction), so that each control volume of the pipe flow can be coupled to the corresponding wall segment. This gives one characteristic inner wall surface temperature for each finite pipe flow control volume.

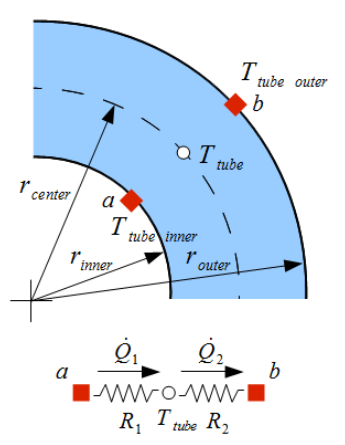

$R_{1} T_{\text {tube }} R_{2}$

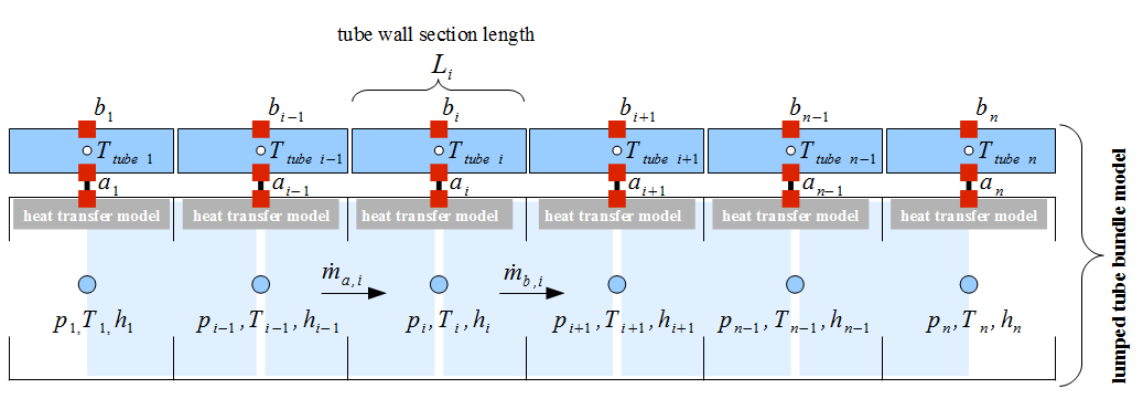

[...... Modelica heat connector (connecting equations: temperatures are set equal, heat flows sum up to zero )

Figure 5. $\quad$ Pipe model [21][22]

In Figure 5 a schematic of the pipe (and flow) with a single conduction node model is presented. The red squares are heat connectors, interfaces used to connect models by equating the temperatures and heat flows of the connected surfaces. The governing equations for each of the pipe nodes represented in Figure 5 are:

$$
\begin{gathered}
R_{1}=\frac{\ln \left(r_{\text {center }} / r_{\text {inner }}\right)}{2 \cdot \pi \cdot L_{i} \cdot k_{\text {tube }}} \\
R_{2}=\frac{\ln \left(r_{\text {outer }} / r_{\text {center }}\right)}{2 \cdot \pi \cdot L_{i} \cdot k_{\text {tube }}} \\
\dot{Q}_{1}=\frac{T_{\text {tube inner } i}-T_{\text {tube } i}}{R_{1}} \\
\dot{Q}_{2}=\frac{T_{\text {tube } i}-T_{\text {tube outer } i}}{R_{2}} \\
C_{\text {tube } i} \cdot \frac{d T_{\text {tube }}}{d t}=\dot{Q}_{1}-\dot{Q}_{2}
\end{gathered}
$$

Where $T_{\text {tube inner } i}, T_{\text {tube } i}, T_{\text {tube outer } i}, r_{\text {center }}, r_{\text {inner }}, r_{\text {outer }}$ and $L_{i}$ are the parameters and variables represented in Figure 5 and $C_{\text {tube } i}$ is the heat capacity of the pipe volume i. The temperatures are expressed in Kelvin $(\mathrm{K})$, the thermal resistances in $(\mathrm{W} / \mathrm{K})$, the heat flow rate $\dot{Q}$ in $(\mathrm{W})$, all the geometric parameters in $(\mathrm{m})$ and the thermal capacity in $(\mathrm{J} / \mathrm{K})$. This model includes the possibility of modeling internal heat generation by adding a simple source term in Eq. (10); this feature is used to simulate the heat tracing mechanism used in the receiver in order to avoid freezing of the salts.

\subsubsection{Forced Convection between the Molten Salts and the Steel Pipe}

The convective heat transfer is defined via a replaceable wall heat transfer model, which defines the relationship between the tube's inner wall temperatures, $T_{\text {tube inner } i}$, the fluid bulk temperatures, $T_{i}$ and the net heat flows $\dot{Q}_{n e t} i$. The heat transfer coefficient $\left(\mathrm{W} / \mathrm{m}^{2} \mathrm{~K}\right), h_{\text {fluid } i}$, is calculated from the Nusselt number correlations evaluated for each control volume, once it has been calculated it is substituted in Newton's convective heat transfer law. 


$$
\dot{Q}_{\text {net } i}=h_{\text {fluid } i} \cdot A_{\text {tube inner } i} \cdot\left(T_{\text {tube inner } i}-T_{i}\right)
$$

Where $A_{\text {tube inner } i}\left(\mathrm{~m}^{2}\right)$ is the area of the inner surface of the pipe within the control volume $i$.

The heat transfer model can be easily changed, so forced internal convection can be modeled for different flow regimes.

To correctly estimate the heat transfer for turbulent pipe flow, which occurs during typical operation, the following Nusselt number correlation, $N u_{\text {fluid }}$, for smooth pipes, as proposed by Gnielinski [23] is used.

\subsubsection{Pressure Drop Model}

The fluid is considered incompressible so the pressure drop though the pipe is caused by the wall friction. The pressure drop is calculated according to the well-known correlations published by Moody [24]. Since the MSL (Modelica Standard Library) does already feature a thorough implementation of pressure drop functions that are valid for the whole flow regime ("detailed wall friction package"), these are used throughout this work.

\subsubsection{HTF Fluid Properties}

Specific media property functions are decoupled from the library components by defining a replaceable "Medium package" in each of them. Basically, all fluid property function names and interfaces are defined within the base class "partial medium". To allow a full replaceability, each specific medium model extends from this base class the "partial medium" and defines the specific medium related relationships by redeclaring each necessary medium property function.

The heat transfer fluid solar salt, as it is not yet modeled in the Modelica Standard Library, was implemented in a previous work [22], based on the properties published by Zavoico [25] and Ferri, Cammi et Al. [26].

\subsection{Radiation Enclosure Model}

\subsubsection{Enclosure Model}

The purpose of building a cavity receiver is avoiding heat losses by creating an enclosure that protects the active surfaces from losing useful energy to the ambient. Radiation heat losses are defined as the heat flow rate, thus solar radiation reflected and thermal radiation emitted by the surfaces, flowing out through the aperture of the cavity.

The enclosure is formed by 5 passive surfaces (ceiling, floor, upper lip and two side lips) the aperture and the variable number of active panels. Each control surface is considered to be at a uniform temperature, the assumptions of gray surfaces and diffuse radiator is supposed for every surface forming the enclosure, except for the aperture, considered to be a black body radiator at a temperature equal to the sky temperature, calculated as a function of the dew point temperature as it was done by Fromberg [27] and Buck [28].

As it was already explained each tube is divided in a series of lumped elements while the radiation enclosure does not divide the surfaces in such elements. The reason why this is done is that if every surface is divided in $\mathrm{n}$ nodes, the number of view factors required to solve the problem will be (number of surfaces $\mathrm{x}$ number of nodes) $)^{2}$. Calculating radiation view factor is computationally expensive so it is preferable to calculate as few as possible. In such way the temperature of each surface of the enclosure is considered to be at the mean temperature of the lumped surface.

The solar radiation focused on the receiver and entering the cavity aperture, is assumed to be equally distributed on every active surface. This heat flow rate is either reflected or absorbed, as every surface is considered to be opaque. it has been assumed that this simplification contributes to achieve the goal of the proposed model, i.e. fast and long-term transient simulations, while including flux maps will 
reduce the speed of the simulations, largely increasing the complexity of the model and reducing the reusability of the modeling proposed approach. Although the calculation of the solar radiation reaching the receiver is not within the scope of the present paper, it is worth mentioning that in the simulations shown below, this concentrated solar radiation is calculated via an efficiency matrix depending on the position of the sun representing the behavior of a heliostat solar field.

The radiosity method is the one implemented to model the radiation heat exchange between all the surfaces, assuming gray and diffuse properties for all the surfaces within the enclosure. The radiosity, $J\left(\mathrm{~W} / \mathrm{m}^{2}\right)$, from a typical surface $i$ is defined by Eq. (12)

$$
\begin{aligned}
& J_{i}=\rho_{i} G_{i}+\varepsilon_{i} E_{b, i} \\
& J_{i}=\rho_{i} G_{i}+\varepsilon_{i} E_{b, i}
\end{aligned}
$$

Where:

- $G_{i}$ is the irradiation, the radiative heat flux incident on surface $i,\left(\mathrm{~W} / \mathrm{m}^{2}\right)$

- $\rho_{i}$ is the reflectivity of the surface,

- $\quad \varepsilon_{i}$ is the emissivity of surface $i$

- $\quad E_{b, i}$ is the black body radiation of surface $i\left(\mathrm{~W} / \mathrm{m}^{2}\right)$.

$$
G_{i}=I_{i}+\sum_{j=1}^{N} J_{j} F_{i-j}
$$

Where:

- $\quad I_{i}$ is the concentrated solar radiation by surface area $\left(\mathrm{W} / \mathrm{m}^{2}\right)$, calculated as the as a product of the direct normal irradiance, the heliostat field area and the efficiency of the field at that time of the day, the resulting heat flow rate is evenly distributed on every active surface.

- $\quad F_{i-j}$ is the view factor from surface $i$ to surface $j$.

The heat transfer with the enclosure of surface $i$ can be expressed by Eq. (14), the heat flow rate is considered to be positive when it goes out of the surface.

$$
\dot{Q}_{\iota}=A_{i}\left(J_{i}-\sum_{j=1}^{N} J_{j} F_{i-j}\right)
$$

As it can be noted, the model takes as inputs the solar irradiance and the view factors. The view factors are geometric parameters accounting for the part of radiation leaving a surface, $i$, and striking another surface $j$. The enclosure model can simulate any geometry, as long as the view factors are calculated previously. These parameters are the only ones that take into account the cavity's geometry. In such way the model flexibility is assured.

Calculating the view factor values is computationally a tough task. To allow the simulation of different cavity geometries, a ray-tracing algorithm has been implemented in R [29] and is explained hereafter. The results of these calculations are the inputs to the radiation enclosure model.

\subsubsection{Ray Tracing Routine for the View Factor Calculation}

The ray tracing algorithm developed for calculating the view factors is based on the Monte Carlo method. The Monte Carlo method is a probabilistic method used to approximate the value of an unknown entity by repeatedly running simulations of random samples. If $f(x)$ is a random function, its integral can be multiplied and divided by an arbitrary probability density function, $p(x)$, without modifying its value, Eq (17). This multiplication allows transforming the integral into an expected value computation problem [30]. 


$$
I=\int f(x) d x=\int \frac{f(x) p(x)}{p(x)} d x=E\left[\frac{f(x)}{p(x)}\right]
$$

The expectation value, on the other hand, can be estimated from $M$ samples, generated with probability density function $p$ :

$$
I=E\left[\frac{f(x)}{p(x)}\right]=\frac{1}{M} \sum_{i=1}^{M} \frac{f\left(x_{i}\right)}{p\left(x_{i}\right)}
$$

Based on this idea a ray tracing algorithm is implemented to calculate the view factor integral, provided in Eq (19).

$$
F_{1 \rightarrow 2}=\frac{1}{A_{1}} \int_{A_{2}} \int_{A_{1}} \frac{\cos \Phi_{1} \cos \Phi_{2} d A_{1} d A_{2}}{\pi r^{2}}
$$

By tracing a large number of rays randomly positioned over a whole surface and over the whole hemispheric directions with a uniform probability density function distribution the previous integral can be estimated.

The ray tracing method developed is based on the work of Glassner [31]. First of all, the ray is generated at surface $i$, being defined by an origin or eye point, $E=\left(x_{E}, y_{E}, z_{E}\right)$, and a direction vector, $\vec{D}=$ $\left(x_{D}, y_{D}, z_{D}\right)$, created as in the work developed by Fang et Al. [5]. Thus the equation for the ray is a function of the origin point, the direction vector and $t$, a positive parameter determining the magnitude in the direction $\vec{D}$ :

$$
P(t)=E+t \vec{D}, \quad t \geq 0
$$

The origin, E, is generated by creating two random numbers; each of them will be a different coordinate and the third coordinate is calculated to satisfy the surface equation. The direction vector is created with two random numbers, $\theta$ and $\varphi$, representing the polar angle and the azimuth angle of the polar coordinates.

$$
D=(\cos \varphi \cos \theta, \cos \varphi \sin \theta, \sin \varphi)
$$

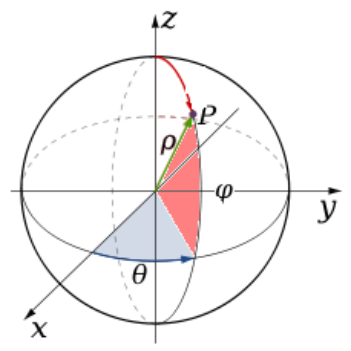

Figure 6. Definition of $\theta$ and $\varphi$.

The ray created is tracked to determine whether it strikes with surface $j$. To do so, the intersection with the plane containing surface $j$ is studied, if the ray intersects that plane it has to be tested whether the ray lays inside the polygon or not.

A point P lies on a plane if it satisfies Eq. (21), where $\vec{N}$ is the normal vector to the surface and Q is a point of the plane.

$$
\vec{N} \cdot(P-Q)=0
$$


To find the intersection point the ray equation is substituted in Eq. (20).

$$
t=\frac{\vec{N} \cdot(Q-E)}{\vec{N} \cdot \vec{D}}
$$

- If $t<0$ then the plane is behind the eye point and there is no intersection.

- If $t \geq 0$ then the intersection point is $E+t \vec{D}$.

- If $\vec{N} \cdot \vec{D}=0$ then the ray is parallel to the plane, and there is no intersection point.

A polygon can be defined by an ordered set of vertices $\left(V_{1}, V_{2}, V_{3}, \ldots\right)$. The normal of the polygon's plane can be found by the simple cross product:

$$
\vec{N}=\left(V_{3}-V_{2}\right) \times\left(V_{1}-V_{2}\right)
$$

The point on the plane's surface is $Q=V_{1}$.

In ray tracing and other applications the original polygon is defined in three dimensions. To simplify computation it is worthwhile to project the polygon and test the point into two dimensions. One way to do this is to simply ignore one component. The best component to ignore is usually that which, when ignored, gives the largest polygon area. This is easily done by taking the absolute value of each component of the polygon plane's normal and finding the largest, as done by Glassner [31]. The corresponding coordinates in the polygon are then ignored.

The "point.in.polygon" function implemented in the "sp package"[32] for $\mathrm{R}$ is used to check if the intersection point lies inside the polygon that defines the surface. Any time that the intersection ray/plane is inside the polygon, the number of rays emitted by surface $i$ and striking surface $j$ is increased by one. In such way the view factor is calculated.

$$
F_{i \rightarrow j}=\frac{\text { number of rays emitted by surface } i \text { striking in surface } j}{\text { number of rays emitted by surface } i}
$$

In the present study, a number of 2.000.000 rays for each view factor calculation resulted big enough to avoid significant variation in numerical view factor calculation. However, a modeler should always check the convergence of the ray tracer results prior to accepting a solution.

\subsubsection{Ray Tracing Routine Validation}

To validate the ray tracing routine implemented to calculate the view factor values, the results obtained with such method are compared to the ones obtained with the analytical expressions found in the literature. The case of two perpendicular rectangles with a common edge is tested, the analytical correlation provided by Hottel [33], Eq. (23), is used for the comparison.

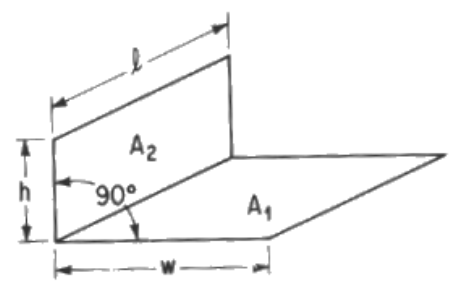

Figure 7. Perpendicular rectangles [34]. 


$$
\begin{aligned}
& F_{1 \rightarrow 2} \\
& =\frac{1}{W \pi}\left(W \tan ^{-1}\left(\frac{1}{W}\right)+H \tan ^{-1}\left(\frac{1}{H}\right)-\sqrt{H^{2}+W^{2}} \tan ^{-1} \frac{1}{\sqrt{H^{2}+W^{2}}}\right. \\
& \left.+\frac{1}{4} \ln \left(\left(\frac{\left(1+W^{2}\right)\left(1+H^{2}\right)}{1+W^{2}+H^{2}}\right)\left(\frac{W^{2}\left(1+W^{2}+H^{2}\right)}{\left(1+W^{2}\right)\left(W^{2}+H^{2}\right)}\right)^{W^{2}}\left(\frac{H^{2}\left(1+W^{2}+H^{2}\right)}{\left(1+H^{2}\right)\left(W^{2}+H^{2}\right)}\right)\right)\right)
\end{aligned}
$$

Where $\mathrm{H}=\mathrm{h} / \mathrm{l}$ and $\mathrm{W}=\mathrm{w} / \mathrm{l}$.

The value obtained with Eq. (25) is 0.2000438 for $\mathrm{h}=\mathrm{l}=\mathrm{w}=2$.

Performing the view factor calculation with the ray-tracing routine the value calculated is 0.200464 , so the error in the calculation is 0.0004202 , negligible.

\subsection{Natural and Forced Convection Model to Ambient}

Convection heat losses play a major role in the performance of a cavity receiver. In the last 20 years several correlations for the Nusselt number have been developed by different authors; these expressions have been later used to model both convective heat losses mechanisms: natural convection heat losses and forced convection heat losses.

The heat transfer coefficient, $h$ and thus, the convective heat loss calculation, is generally based on the Nusselt number, $\mathrm{Nu}$.

$$
\begin{gathered}
\dot{Q}_{c o n v, i}=h_{i} A_{s, i}\left(T_{s, i}-T_{a m b}\right) \\
N u_{i}=\frac{h_{i} L_{c}}{k_{i}}
\end{gathered}
$$

$\dot{Q}_{\text {conv }, i}$ is the total heat flow rate lost from surface i to the bulk air and leaving the cavity. The Nusselt number, $N u_{i}$, is calculated for every surface within the cavity receiver, as indicated later in this section, and thus the heat transfer coefficient, $h_{i}$, is obtained. The ratio of the Grashof number to the square of the Reynolds number is a useful indicator of the driving forces of the flow and therefore what kind of convection mechanism has to be considered in transfer model, this ratio is called Richardson number. By using the criteria introduced by Kreith [35] the transition between forced convection and natural convection is modeled according to the following: when the Richardson is greater than 10 only natural convection is considered while if it is lower than 0.7 only forced convection is considered. The proposed modeling approach is based in this criterion to take into account the transition between natural convection and forced convection. The proposed model aims to be reusable for the simulation of different geometries and configurations of cavity receivers despite the complexity of the flow patterns inside the cavity, thus the error introduced by using the Richardson criteria regardless of the forced flow direction is considered tolerable. A homotopy factor makes the transition smooth between the two regimes, "simulating" the mixed convection.

The expression used by Siebers and Kraabel [6] to predict forced convection heat losses, widely used in the literature, is based more on speculation than it is on engineering judgment, as stated by the authors themselves. For this reason, in the present work, a new approach to model forced convection has been considered. This approach consists in approximating the wind speed inside the cavity by an estimator based on a previous work of Clausing [36], in which the author estimated the velocity of the air going out through the aperture of the cavity receiver by Eq. (26).

$$
v_{c}=0.5 \sqrt{\left(C_{1} v_{b}\right)^{2}+\left(C_{2} v\right)^{2}}
$$




$$
v_{b}=\sqrt{g L_{c} \beta\left(T_{s}-T_{a m b}\right)}
$$

Where $v_{c}$ is the velocity of the air inside the cavity, $v_{b}$ is the buoyant velocity and $v$ is the wind velocity. The buoyant velocity is the velocity induced in the bulk air when only natural convection is present, $g$ is the acceleration due to gravity, $L_{c}$ is the height of the aperture, $T_{s}$ is the cavity average temperature and $\beta$ the volume coefficient of expansion evaluated at the mean temperature between the ambient temperature and the cavity average temperature. If the constants are taken as $C_{1}=1$ and $C_{2}=1 / 2$ as done by Clausing [7] the results obtained for the velocity of the air within the cavity agrees quite well with the results obtained by Fang [5] where the velocity of the air inside a cavity receiver is studied for different wind speeds and angles of incidence through CFD simulations. It also agrees with the data published by McMordie [37], which states that wind speeds below $15 \mathrm{mph}$ (about $7 \mathrm{~m} / \mathrm{s}$ ) were indistinguishable in a cavity receiver independently of the angle of incidence, meaning that free convection is the dominant mechanism.

Preliminary tests have shown how the influence of increasing the value of $C_{2}$ does not influence significantly natural convection heat losses but it does influence significantly wind velocities greater than $8 \mathrm{~m} / \mathrm{s}$. In such way reconsidering the value used for the estimator of the velocity inside the cavity seems to be necessary in order to better predict the transition from natural convection to mixed convection.

For the forced convection heat transfer coefficient calculation, the correlation in Eq. (28) [38] is implemented.

$$
N u=\frac{h L}{k}=0.037 \operatorname{Re}_{L}^{0.8} \operatorname{Pr}^{1 / 3} \text { for } 0.6 \leq \operatorname{Pr} \leq 60 \text { and } 5.10^{5} \leq R e_{L} \leq 10^{7}
$$

For the natural convection, the correlation proposed by Clausing [7] is implemented. After a deep review of the related literature, which can be found in [11], this one is chosen because it allows predicting the natural convection heat losses for every surface inside the cavity receiver. The author studied the buoyant velocity induced in the cavity by the buoyancy forces created by the high surface temperatures. He divided the cavity in two zones, the convective zone, where the natural convection heat exchanges occur, and the stagnant zone, with a low influence in convective heat losses. The natural convection heat loss model is connected to the lumped pipe model already described, in particular it is connected to the outer conduction heat connector. The same is done for the passive surfaces. For each control volume, the heat transfer coefficient is calculated according to the local fluid properties using a detailed air model (adaptation of the media "DryAirNasa" in the MSL), and the local flow velocity. Then, for each control surface the final heat transfer coefficient is obtained.

A detailed explanation of the natural convection correlations is out of scope and it is referred to the original manuscripts [7]. The approach presented here and the values of the constants for the estimator should be tested in the future in large scale experiments or through CFD analysis.

\subsection{Conduction through the Insulation Model}

Conduction through the insulation layer is implemented as explained in Section 3.3. The thermal resistances, $R$, are adapted to the geometry of the simulated surface.

$$
\begin{aligned}
R_{\text {planar }} & =\frac{\Delta x}{A k} \\
\mathrm{R}_{\text {semicylinder }} & =\frac{\ln \left(\frac{r_{2}}{r_{1}}\right)}{k L \theta}
\end{aligned}
$$

Where: 
- $\mathrm{k}$ is the thermal conductivity $\left(\mathrm{W} / \mathrm{m}^{2} . \mathrm{K}\right)$

- $\Delta x$ is the insulation thickness (m)

- $\quad r_{2}$ and $r_{1}$ are the outer and inner radius (m)

- $\theta$ is the angle covered by the semicylinder (rad) and

- $\quad L$ is the semicylinder length $(\mathrm{m})$.

Thermal conduction resistance for a planar body, Eq. (29), and thermal conduction resistance for a semicylindrical body, Eq. (30).

\subsection{Outer Surfaces Heat Loss Model}

The heat flow rate conducted through the insulation layer is lost to the ambient by radiation and mixed convection. Again, in the convection model, for each node the heat transfer coefficient is calculated according to the local air properties, and the local flow velocity, equal to the wind velocity. The corresponding Nusselt correlations are the ones for flat plates [38] as the cylinder surface can be approximated to a flat plate as it satisfies Eq. (31) [38]. The sky is modeled as a black body radiator at the sky temperature, calculated as in Section 3.2.1.

$$
\mathrm{D} \geq \frac{35 \mathrm{~L}}{\mathrm{Gr}^{\frac{1}{4}}}
$$

Where:

- $\quad \mathrm{D}$ is the cylinder diameter and $\mathrm{L}$ is the cylinder length $(\mathrm{m})$

- $\mathrm{Gr}$ is the Grashof number.

The condition imposed by Eq. (31) would be satisfied for all the reasonable values of $L$ and $D$ as the Grashof number divided by the third power of the characteristic length is always over $10^{9}$ for all the cases tested.

The global solar irradiation incident on the ceiling of the cavity is considered via the following equation:

$$
\dot{Q}_{\text {solar ceiling }}=\left(D N I \cdot \cos \theta_{\text {zenith }}+I_{\text {diffuse horizontal }}\right) \alpha_{\text {surface }} A_{\text {ceiling }}
$$

Where:

- $\quad$ DNI is the direct normal irradiance $\left(\mathrm{W} / \mathrm{m}^{2}\right)$

- $\theta_{\text {zenith }}$ is the sun zenith angle (rad)

- I Iiffuse horizontal is the diffuse horizontal irradiation $\left(\mathrm{W} / \mathrm{m}^{2}\right)$

- $\alpha_{\text {surface }}$ is the absorptivity of the surface

- $A_{\text {ceiling }}$ is the outer area of the ceiling $\left(\mathrm{m}^{2}\right)$

The global solar irradiation incident on the outer wall is considered according to Liu and Jordan [39], assuming a uniform distribution of the diffuse radiation over the sky dome, and furthermore assuming an average ground reflectance, $\rho_{\text {ground }}$, of 0.2 :

$$
\begin{gathered}
\dot{Q}_{\text {solar wall }}=\left(D N I \cdot \sin \theta_{\text {zenith }} A_{\text {projection wall }}+\frac{I_{\text {diffuse horizontal }}}{2} A_{\text {wall }}\right. \\
\left.+I_{\text {global horizontal }} \rho_{\text {ground }} A_{\text {wall }}\right) \alpha_{\text {surface }}
\end{gathered}
$$

Where $A_{\text {wall }}$ is the wall area $\left(\mathrm{m}^{2}\right)$ and $I_{\text {global horizontal }}$ the global horizontal irradiance $\left(\mathrm{W} / \mathrm{m}^{2}\right)$. 
The spillage is modeled as a percentage of the total radiation focused in the receiver, distributed to the upper lip and both side lips.

\subsection{Schematic of the Model}

Figure 8 illustrates the schematic of the model implemented to clarify what has been described trough Section 3. The simplified net of thermal resistances is shown for one of the active panels, the radiative resistances are depicted in green while the convective resistance in blue, the left side is the zoom of the pipe with the model previously described, and the thermal resistance to conduction through the insulation layer is also depicted in orange.

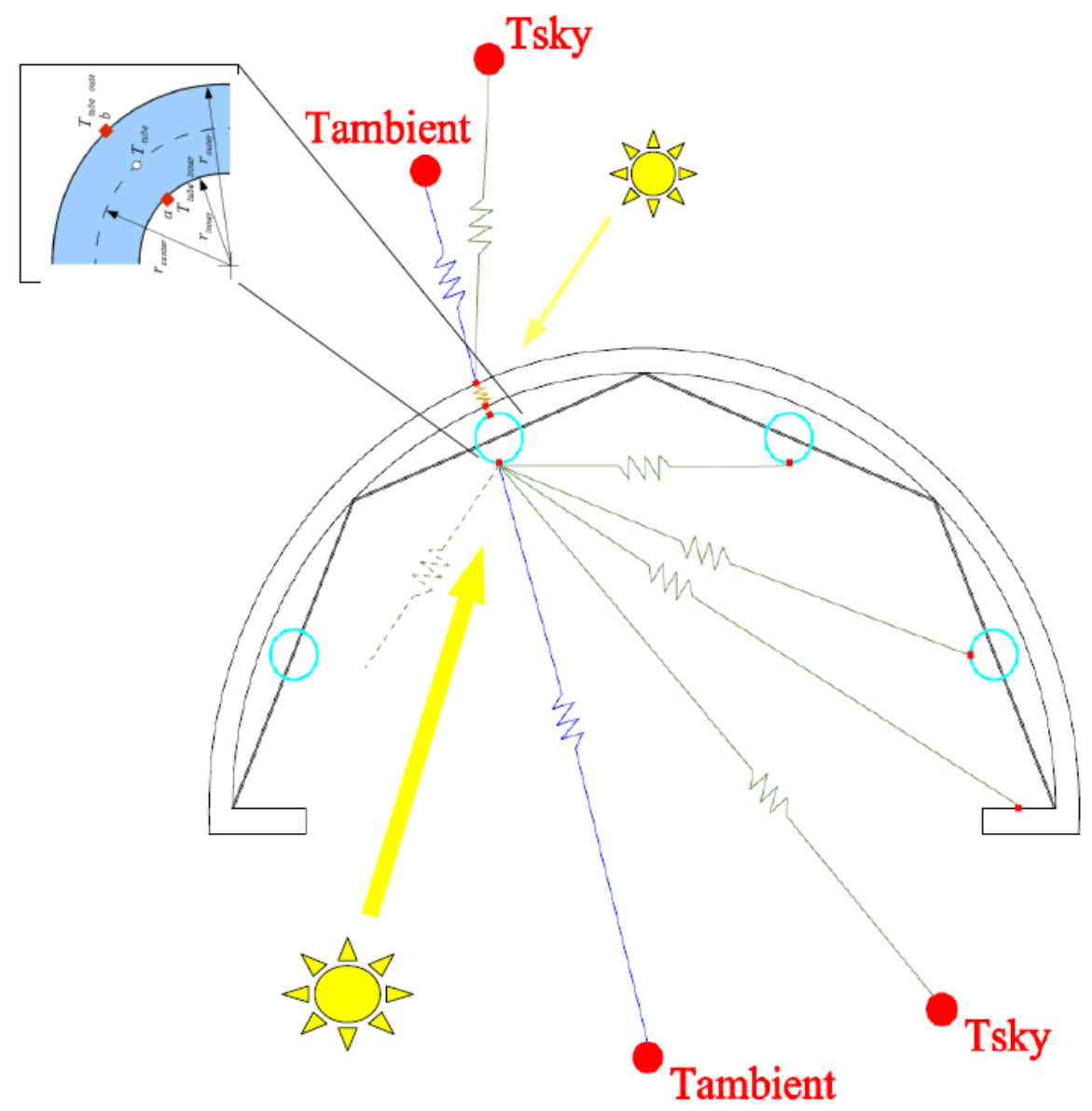

Figure 8. Schematic of the model.

\subsection{Model Translation}

The model programmed in Modelica code is translated into numerical simulation code using a commercial Modelica tool, and then solved using the Radau IIa-order 5 stiff solver, Radau IIa is an implicit variablestep Runge-Kutta method of order 5 [40]. This algorithm applies an implicit method for the numerical integration of the governing ordinary differential equations.

\section{Control Strategy: PI Adaptive Neural Controller}

Due to the large variability inherent to the weather conditions and the periodicity of the solar resource, the value of the outlet HTF temperature is continuously changing throughout the operation of a solar receiver. 
An appropriate control strategy is required to provide a relatively constant temperature at the outlet of the receiver at varying ambient conditions. The aim of the control strategy is regulating the outlet temperature of the receiver by suitably adjusting the HTF mass flow rate through the receiver.

\subsection{Receiver Dynamics}

The controlled variable, as previously commented is the HTF outlet temperature, by regulating the mass flow rate entering the panels of the receiver the temperature at the outlet can be regulated.

The dynamics of the receiver are nonlinear; this means that there is not a unique transfer function correlating the mass flow rate and the outlet temperature of the receiver for the whole operating range.

In the control strategy presented in this paper, five linearizations of the receiver are studied for the cavity receiver for five different mass flow rates, defining five different operating points that will be used to design five different linear controllers, as in the work done by Pickhardt [41]. The mass flows considered are 220, $180,140,100$ and $60 \mathrm{~kg} / \mathrm{s}$. To obtain the transfer function of the model for each of these operating points, the step response has to be studied for each of them. The step response of the system is found to be a first order system response. A first order system can be described by a transfer function of the form of Eq. (34)

$$
G(s)=\frac{T_{H T F \text { outlet }}(s)}{\dot{M}(s)}=\frac{K}{\tau s+1}
$$

Where:

- $\mathrm{K}$ is the gain, calculated as shown in Eq. (35) and

- $\tau$ is the time constant, is defined as the time required for the output to reach a value of $63.2 \%$ of its nominal value.

$$
K=\frac{\text { Temperature at the steady state }}{\text { Mass flow rate }}
$$

Once the dynamics are characterized, the control strategy can be defined.

\subsection{Adaptive Control Strategy}

As the dynamic characteristics change with the mass flow rate, the controller is changed too, an adaptive PI controller is proposed to control the receiver in the closed loop, see Figure 9. This means that for the proposed controller, its parameters; gain and time constant of the integrator are going to change as the mass flow rate changes.

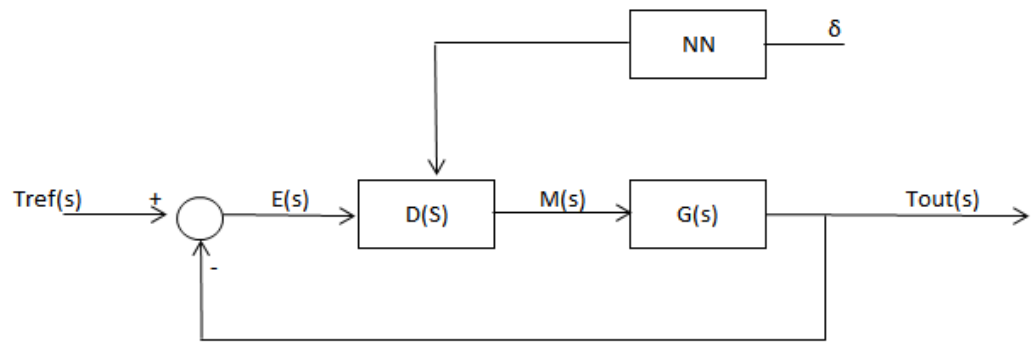

Figure 9. Control loop.

$\mathrm{T}_{\text {ref }}(\mathrm{s})$ is the desired HTF outlet temperature, $\mathrm{T}_{\text {out }}(\mathrm{s})$ is the temperature at the outlet, $\mathrm{G}(\mathrm{s})$ is the receiver's transfer function Eq. (34), D(s) is the transfer function of the controller, E(s) is the difference between the desired temperature and the temperature at the outlet and $\mathrm{M}(\mathrm{s})$ is the control action. At last, NN stands for 
the two neural networks used as interpolators to adapt the controller parameters and $\delta$ is an estimator of the operating point Eq. (36).

As the controller has to be robust, the operating point defining the dynamics of the receiver is decoupled from the current measured mass flow rate. For this reason a characteristic value $\delta$, which is correlated to the mass flow flowing through the tubes of the panels, is calculated in Eq. (36). This parameter is used to calculate the operating point and thus the parameters required by the PI adaptive controller, gain and time constant of the integrator.

$$
\delta=\frac{D N I}{T_{\text {ref }}-T_{\text {inlet }}}
$$

$\delta$ is a function of the direct normal irradiance (DNI), the reference temperature (desired temperature for the HTF at the outlet), and the inlet temperature.

The mass flow can be expressed as a function of the heat flow rate absorbed, $Q_{a b s}^{\cdot}$ the specific heat capacity, $\mathrm{c}_{\mathrm{HTF}}$, and the temperature difference between the HTF inlet and outlet temperature, $T_{\text {inlet }}$ and $T_{\text {outlet }}$, Eq. (37).

$$
\dot{m}=\frac{\dot{\dot{a b s}}}{c_{H T F}\left(T_{\text {outlet }}-T_{\text {inlet }}\right)}
$$

While the heat flow rate absorbed can be written as:

$$
Q_{a b s}^{\cdot}=\eta_{s f} \eta_{\text {thermal }} A_{h f} D N I
$$

Where:

- $\eta_{s f}$ is the solar field efficiency

- $\eta_{\text {thermal }}$ is the thermal efficiency of the receiver

- $A_{h f}$ is the area of the heliostat field

By substituting Eq. (38) in Eq. (37) and considering that in the steady state $T_{\text {outlet }}=T_{\text {ref }}$ the relation between $\dot{m}$ and $\delta$ is obtained.

$$
\dot{m} \approx \frac{\eta_{s f} \eta_{\text {thermal }} A_{h f} D N I}{c_{H T F}\left(T_{\text {ref }}-T_{\text {inlet }}\right)}=\frac{\eta_{s f} \eta_{\text {thermal }} A_{h f}}{c_{\text {HTF }}} \delta
$$

Solar thermal systems are generally slow due to the slow dynamic and their high thermal inertia. If the Fourier transform is applied to a first order system with a slow dynamic behavior, the pole (zero of the denominator of the transfer function) of the transfer function for the different operating points is close to zero. To boost the performance of this kind of systems a good technique to design the PI controller is cancelling the slow pole of the plant with the PI controller. If the plant transfer function is correctly identified, the slow pole would be cancelled for each operating point through the adjusted integrator time constant of the controller. The last parameter, the gain would be chosen to meet another specification, in this case a steady state error to ramp excitation smaller than 0.02 .

The main goal when controlling a system is to do it in the most accurate way for the whole operating spectrum. To achieve this purpose two neural networks are used as interpolators. By taking the operating point $\delta$ as an input they provide the appropriate value for the gain and the time integral constant for the whole operating range, this is the mechanism used to transform a linear control strategy into an adaptive controller. 


\subsection{Neural Networks used as Interpolators}

The reason why two neural networks are used is that they can learn any nonlinear function by adjusting the weights of each neuron. Each neural network learns a different function; one is used for the gain function and the other for the time integrator constant function of the PI controller. By showing examples to the network of both inputs and desired outputs, the network adjusts its parameters to reproduce the desired result. This is achieved by using a training algorithm like the Levenberg-Marquardt algorithm. Even though in this case the two neural networks are trained off-line, presenting values of $\delta$ as inputs and their corresponding gain and time constant of the integrator as the desired outputs, there are several algorithms that allow training neural networks on-line using different control strategies, this means that they learn while the system is working. This allows the neural network to adjust its parameters to meet the changing dynamics of systems over time.

The two neural networks are defined as networks formed by one hidden layer, with 3 neurons in this layer, and a linear output neuron. The examples presented are the desired output gain and time integral constant for the five different operating conditions.

\subsection{Control Loop and Implementation in Modelica}

If the controlled systems designed for the five operating points are stable in the closed loop, the properly interpolated controllers might be stable as well. As it is shown in Figure 9 a unitary feedback simplification is assumed, $\mathrm{D}(\mathrm{s})$ is the PI controller and $\mathrm{NN}$ are the two neural networks.

The model implemented in Modelica takes as inputs the reference temperature or set point, the measured outlet temperature, the inlet temperature and the pump operation limits. The controller implemented in Modelica is based on the MSL controller model "PI controller with limited output, anti-windup compensation and set point weighting" [42]. The controller gain and the integral time constant are defined as variables, so they are estimated by a nonlinear function.

The model implemented for the controller includes a parameter that allows disconnecting the controller when the receiver is not operated to prevent the integral of the error from becoming too large and causing computational problems.

The control strategy also includes a heat tracing mechanism, which heats the remaining molten salts in the tubes of the receiver when the controller is disconnected due to the low direct normal irradiance. In such way the solidification of the molten salts is avoided. This mechanism is implemented through a proportional controller $(\mathrm{W} / \mathrm{K})$, multiplying the difference between the lowest limit fixed for the salts, $265^{\circ} \mathrm{C}$, and the lowest temperature measured at the tubes in the panels.

\section{Simulations}

In this section, the flexible transient model programmed in Modelica is studied for a specific geometry. For this geometry, the adaptive control strategy is implemented and the results are tested over a period of 6 days. Different days of the simulation performed are analyzed in detail to check the plausibility of the results and the goodness of the controller designed.

\subsection{Studied Geometry}

One of the main features of the present model is its large flexibility, allowing the simulation of different geometries. To test the plausibility of the results provided by the model, the geometry of the receiver is fixed. The geometry, Table 1, is similar to the geometry of PS10 solar power plant in Sanlucar la Mayor, Spain. The fluid used as HTF is molten salts a mixture of $60 \% \mathrm{NaNO}_{3}$ and $40 \% \mathrm{KNO}_{3}$ (weight percent). 


\begin{tabular}{cc}
\hline \multicolumn{2}{c}{ Geometric parameters } \\
\hline $\boldsymbol{R}_{\boldsymbol{c}}$ & $7 \mathrm{~m}$ \\
$\boldsymbol{H}_{\boldsymbol{c}}$ & $12 \mathrm{~m}$ \\
$\boldsymbol{e}_{\boldsymbol{i n s u}}$ & $0.4 \mathrm{~m}$ \\
$\boldsymbol{w}_{\boldsymbol{s l}}$ & $1.25 \mathrm{~m}$ \\
$\boldsymbol{w}_{\boldsymbol{u l}}$ & $1 \mathrm{~m}$ \\
$\boldsymbol{n}_{\boldsymbol{p a n}}$ & 4 \\
$\boldsymbol{n}_{\boldsymbol{t u b e s}}$ & 300 \\
$\boldsymbol{e}_{\boldsymbol{p i p e}}$ & 0.0025 \\
Number of nodes & 1 \\
\hline Number of conduction nodes & 1 \\
\hline
\end{tabular}

Table $1 \quad$ PS-10 like cavity receiver geometric parameters.

The view factors, 100 values, are calculated with the ray tracing routine explained above and used as input for the receiver model.

\subsection{PI Adaptive Controller}

The control strategy defined in section 4 is implemented for the PS10-like cavity receiver. The design operating conditions are showed in Table 2.

\begin{tabular}{ccc}
\hline \multicolumn{3}{c}{ Simulation Parameters } \\
\hline DNI & 800 & $\mathrm{~W} / \mathrm{m} 2$ \\
\hline Inlet Temperature & 280 & ${ }^{\circ} \mathrm{C}$ \\
\hline Outlet temperature & 565 & ${ }^{\circ} \mathrm{C}$ \\
\hline Ambient temperature & 20 & ${ }^{\circ} \mathrm{C}$ \\
Wind speed & 6 & $\mathrm{~m} / \mathrm{s}$ \\
\hline Wind direction & 0 & $\mathrm{rad}$ \\
\hline Relative Humidity & 15 & $\%$ \\
\hline Atmospheric Pressure & 101325 & $\mathrm{~Pa}$ \\
\hline Solar Field Area & 91500 & $\mathrm{~m} 2$ \\
\hline Focused Radiation & $5,16.10^{7}$ & $\mathrm{~W}$ \\
Date and hour & $21 \mathrm{st}$ of June, $11 \mathrm{a} . \mathrm{m}$. \\
\hline
\end{tabular}

Table 2 Design operating conditions.

At these conditions, the five linearization are studied by calculating the corresponding value of the operating point, $\delta$, the linearized transfer function of the receiver, $\mathrm{G}(\mathrm{s})$, and the parameters of the controllers $\mathrm{D}(\mathrm{s})$ are calculated as explained in 4 , the results obtained are shown in Table 3. 


\begin{tabular}{|c|c|c|c|}
\hline$\dot{m}(\mathrm{Kg} / \mathbf{s})$ & $\delta$ & G(s) & $\mathrm{D}(\mathrm{s})$ \\
\hline 220 & 7.5 & $\frac{1.046}{2167 s+1}$ & $\frac{2167 s+1}{s}(57.4)$ \\
\hline 180 & 6.13 & $\frac{1.4}{2018 s+1}$ & $\frac{2018 s+1}{s}(42.86)$ \\
\hline 140 & 4.88 & $\frac{2.034}{1856 s+1}$ & $\frac{1856 s+1}{s}(29.5)$ \\
\hline 100 & 3.2 & $\frac{3.4}{1580 s+1}$ & $\frac{1580 s+1}{s}(17.65)$ \\
\hline 60 & 2.19 & $\frac{7.5}{1231 s+1}$ & $\frac{1231 s+1}{s}(8)$ \\
\hline
\end{tabular}

Table $3 \quad$ Controller designed and linearized plant model for the different operating points.

The pole of the receiver transfer function is close to 0 , as expected, the non-controlled system response is thus too slow. As it can be seen in Table 3, the zero of the controller cancels the identified pole of the plant.

For the simulations carried out, when $\delta$ is lower than 1.3 high setpoint temperatures cannot be achieved because the mass flow needed to pump to achieve the desired outlet temperature is below the minimum system mass flow assumed to be $20 \mathrm{~kg} / \mathrm{s}$, and thus the receiver stops working and the heliostats are defocused.

\subsection{Transient Simulations}

The transient simulations presented in this section show the plausibility of the proposed model. For these simulations, a detailed weather data base of Nevada containing meteorological data (time, direct normal irradiance, global horizontal irradiance, diffuse horizontal irradiance, temperature, wind speed, wind direction, relative humidity and atmospheric pressure) each 3 minutes has been used. Figure 10 shows the Modelica classes used for the simulations, a source and a sink, the receiver programmed, the controller and the heliostat field. 


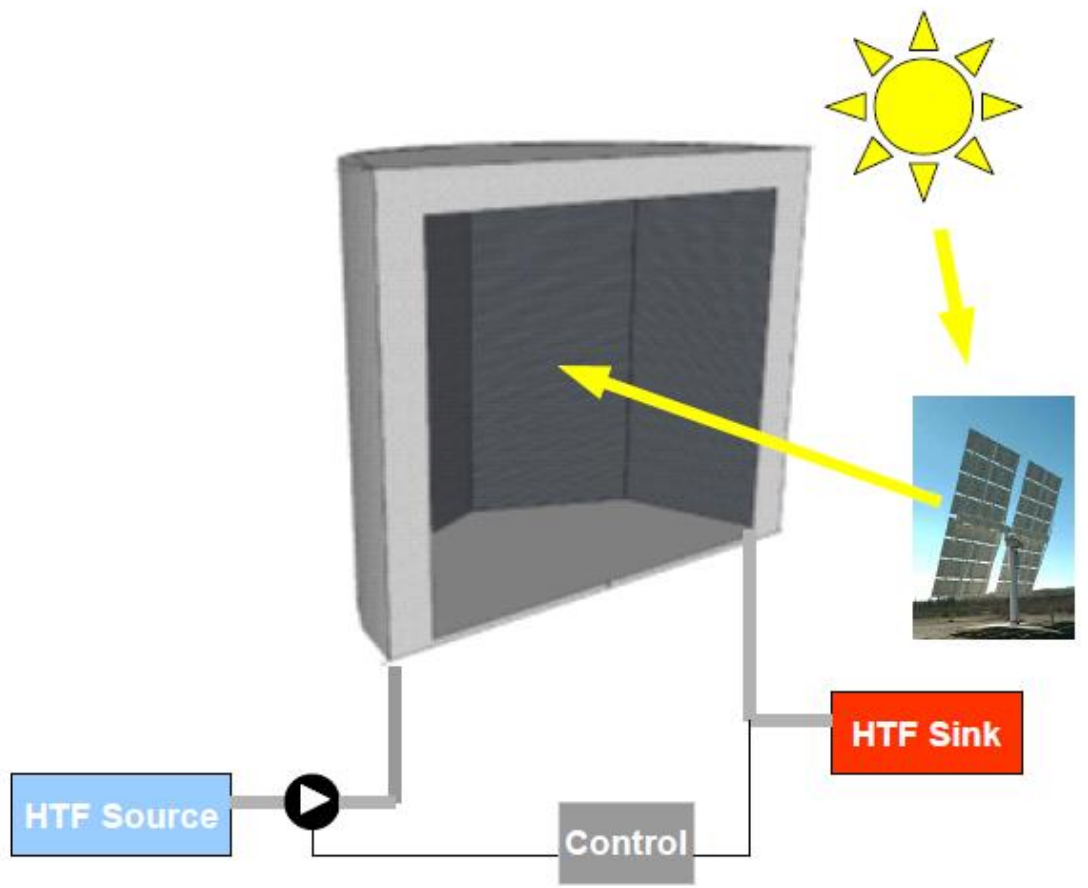

Figure 10. Components of the simulation.

\subsubsection{Analysis of the Receiver Performance}

During a week with DNI rather continuous, i.e. clear days taken from the BSRN database in Nevada, USA, the plausibility of the results of the model implemented in Modelica are tested. For this simulation, results are taken every 5 seconds, the simulation lasted 10 minutes in a Pentium 4 at $2.8 \mathrm{GHz}$ computer. The model satisfies one of the first goals, fast transient simulation.

Figure 11 shows the DNI, set-point temperature, HTF outlet temperature and the mass flow rate. As it can be seen, the outlet temperature perfectly tracks the set-point temperature over the day, during the night the heat tracing mechanisms controls the temperature of the molten salts fixing its value to $270{ }^{\circ} \mathrm{C}$. The outlet temperature is not able to track the reference only when the DNI falls during the second day of simulation and is drastically dropped to zero for several minutes. The efficiency, defined as the ratio power absorbed by the heat transfer fluid to the total solar radiation focused onto the receiver, reaches a maximum value of 90.8\% during the six day simulation, and as it is shown, the mass flow rate does not oscillate to keep the outlet temperature at the desired value. 


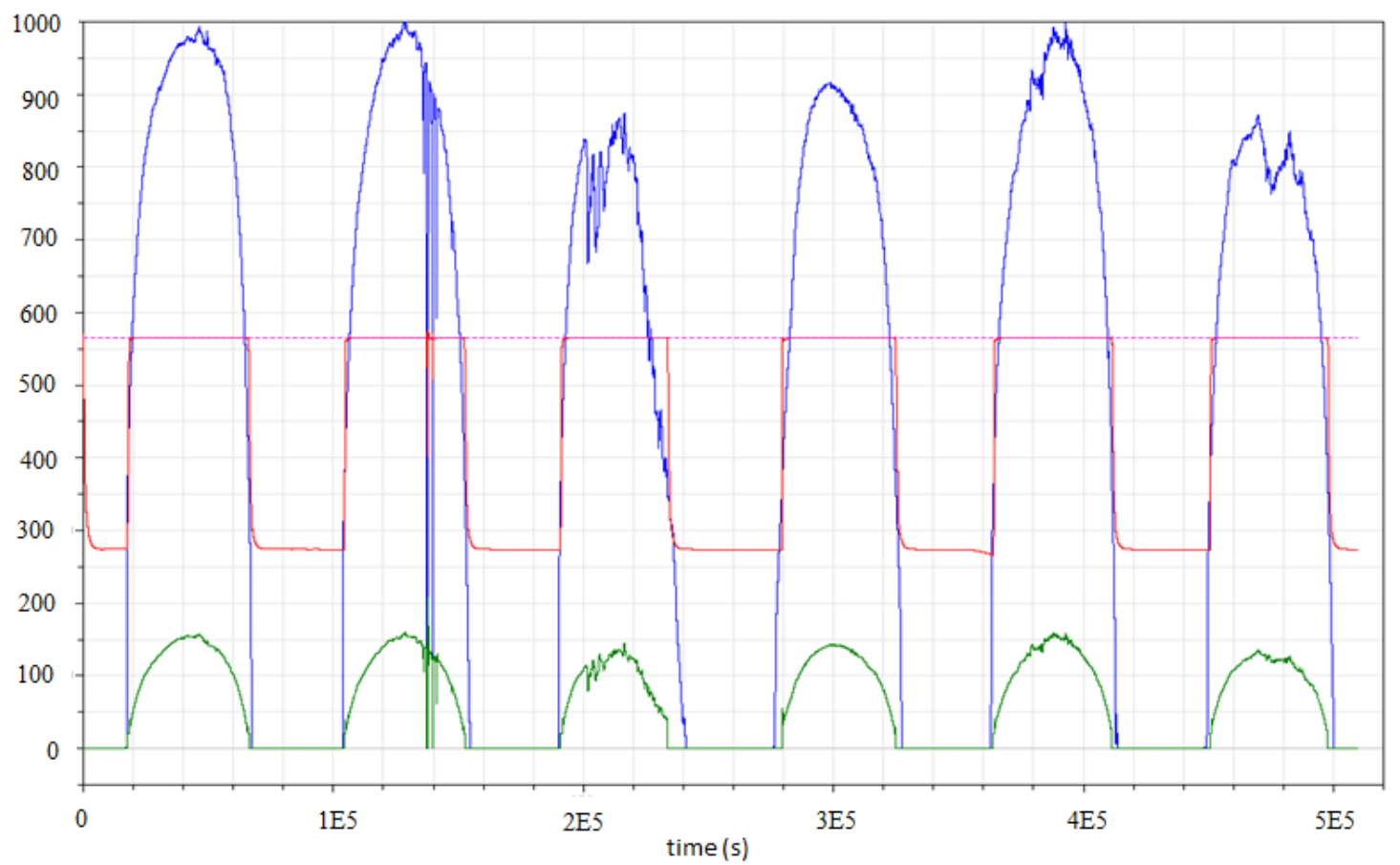

Figure 11. DNI (W/m $\mathrm{m}^{2}$ - blue line $), \mathrm{HTF}$ outlet temperature $\left({ }^{\circ} \mathrm{C}\right.$-red line $)$, set-point temperature $\left({ }^{\circ} \mathrm{C}\right.$ pink dotted line), mass flow rate( $\mathrm{kg} / \mathrm{s}$-green dashed line).

To analyze in a more detailed manner the performance of the cavity receiver, the scope is focused on the $5^{\text {th }}$ day of simulation $(25 / 6 / 2008)$.

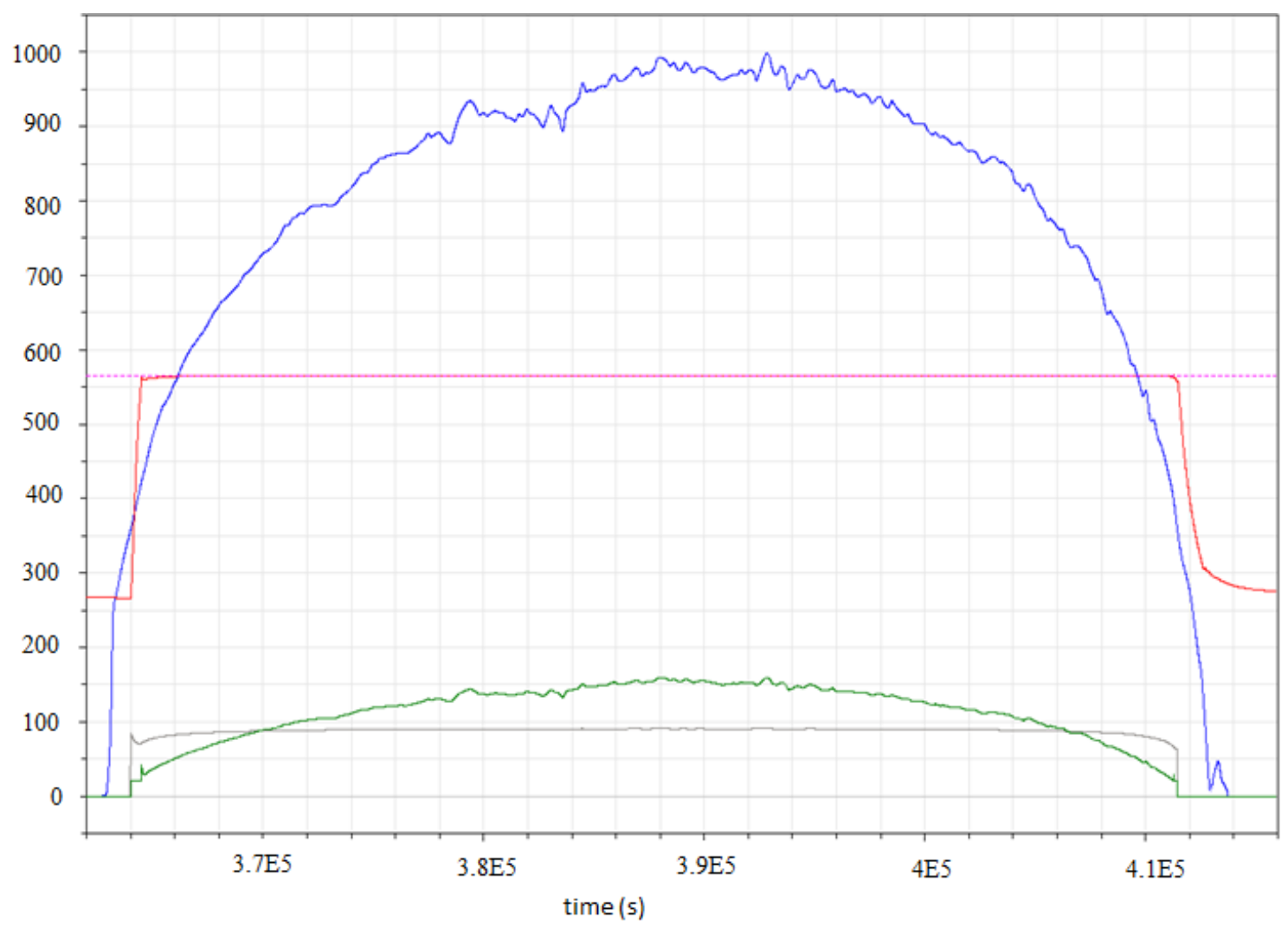

Figure 12. DNI (blue line), HTF outlet temperature (red line), set-point temperature (pink dotted line), mass flow rate (green dashed line) and efficiency of the receiver (gray line) (25/6/2008). 
Figure 12 reveals how the efficiency of the receiver increases as the DNI is increased, while the HTF outlet temperature is constant during the operation the day. The HTF temperature is fixed by the controller, thus the temperature in the surfaces of the active panels is also "fixed". In this way, largely increasing the concentrated radiation only increases the reflective heat losses, while conduction and convection heat losses are relatively constant, see Figure 13. In such way, the efficiency of the receiver is increased as the power focused on the panels is increased. The variations existing in the convective heat losses in Figure 13 are mainly caused to the variations in the wind conditions and the ambient temperature.

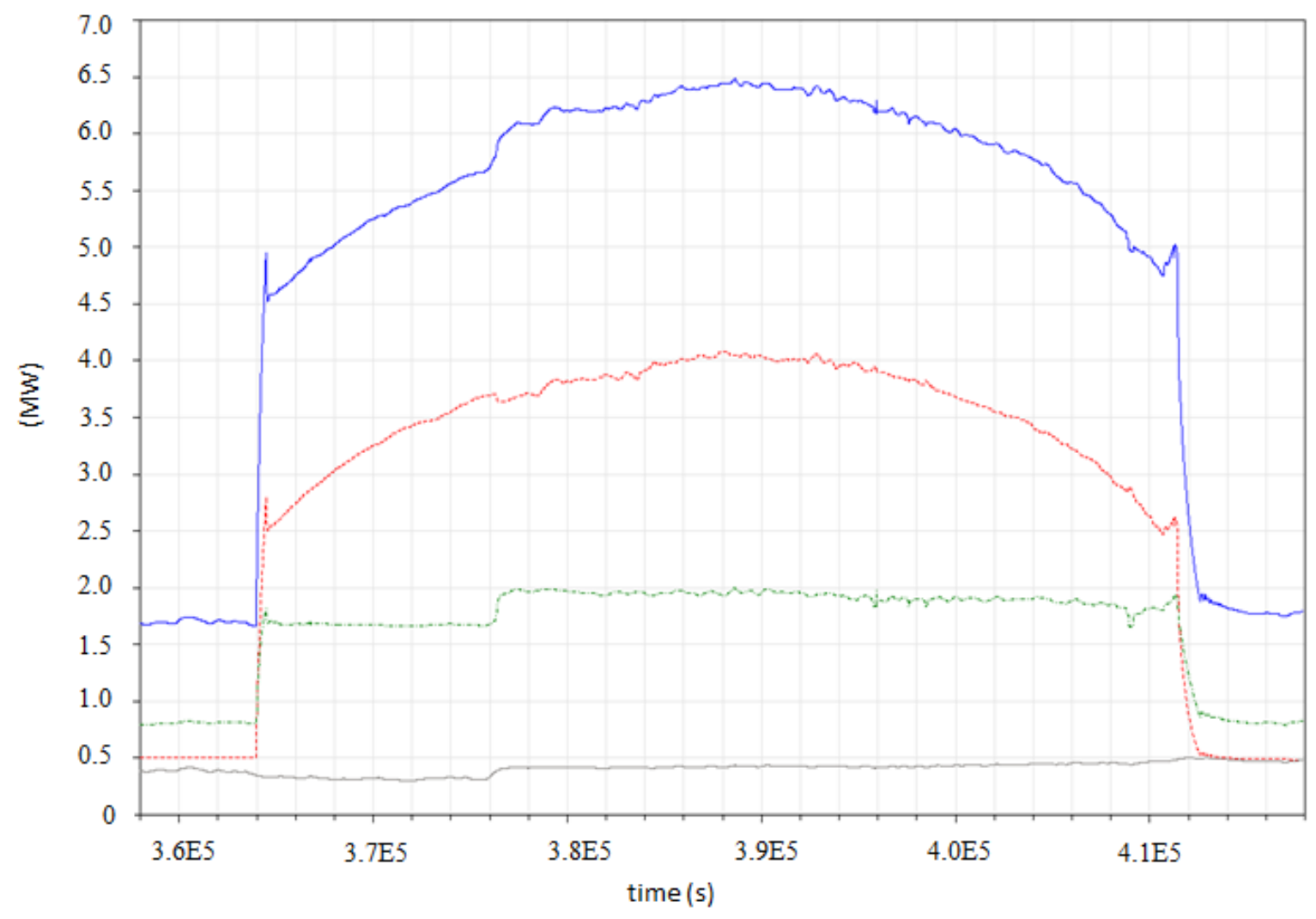

Figure 13. Total heat losses (blue line), radiation heat losses (red dashed line), convective heat losses (green dashed-dotted line) and conduction heat losses (gray line).

A detailed analysis of convective heat losses is shown in Figure 14, where in the first image the total convective heat losses are plotted (blue line) with the convective heat losses from the hottest active panel(red line), in the second one, the wind speed at the height of the receiver (blue), the buoyant velocity (gray) and the velocity of the air inside the cavity (green dashed dotted) are plotted, in the third image, the ratio between the Grashof number and the square of the Reynolds number is plotted (green line) the boundaries representing pure natural convection (red dashed line) and pure forced convection (blue dashed line) according to Kreith [35] are also represented, at last the ambient temperature (blue) the bulk temperature (green dashed) and the temperature of the air leaving the cavity (red dashed dotted) are plotted

The first peak in the total convection heat losses in Figure 14 is caused by the increase in the temperature of all the surfaces of the cavity receiver caused by the radiation focused on the panels when the operation of the plant starts. As it can be seen, the ratio of the Grashof number to the square of the Reynolds number is almost during the whole simulation greater than the upper limit fixed for pure natural convection, even though wind velocities in the exterior of the receiver are considerably high. These results suggest that the coefficients of the estimator used to model the velocity of the air inside might be underestimating the velocity of the air inside the cavity. 
As expected the bulk temperature is higher when the driving heat transfer mechanism is natural convection and the movement of the air inside the cavity is low and thus a slight amount of air leaves the cavity. To conclude the analysis of the heat losses Figure 15 shows the percentage of the total energy lost by the different heat transfer mechanism during the whole day. These percentages may vary from day to day depending on the weather conditions.
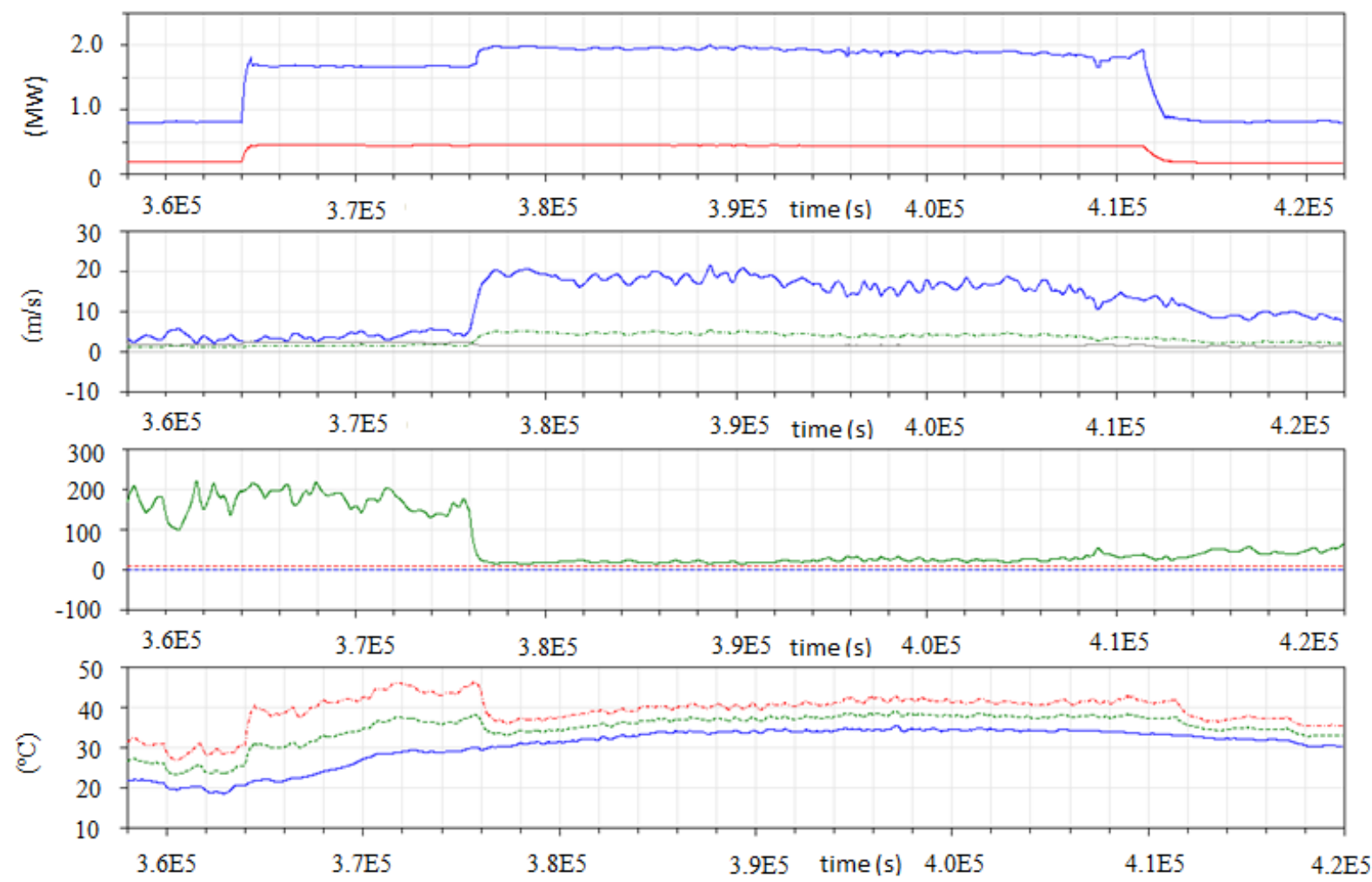

Figure 14. Convective heat losses analysis.

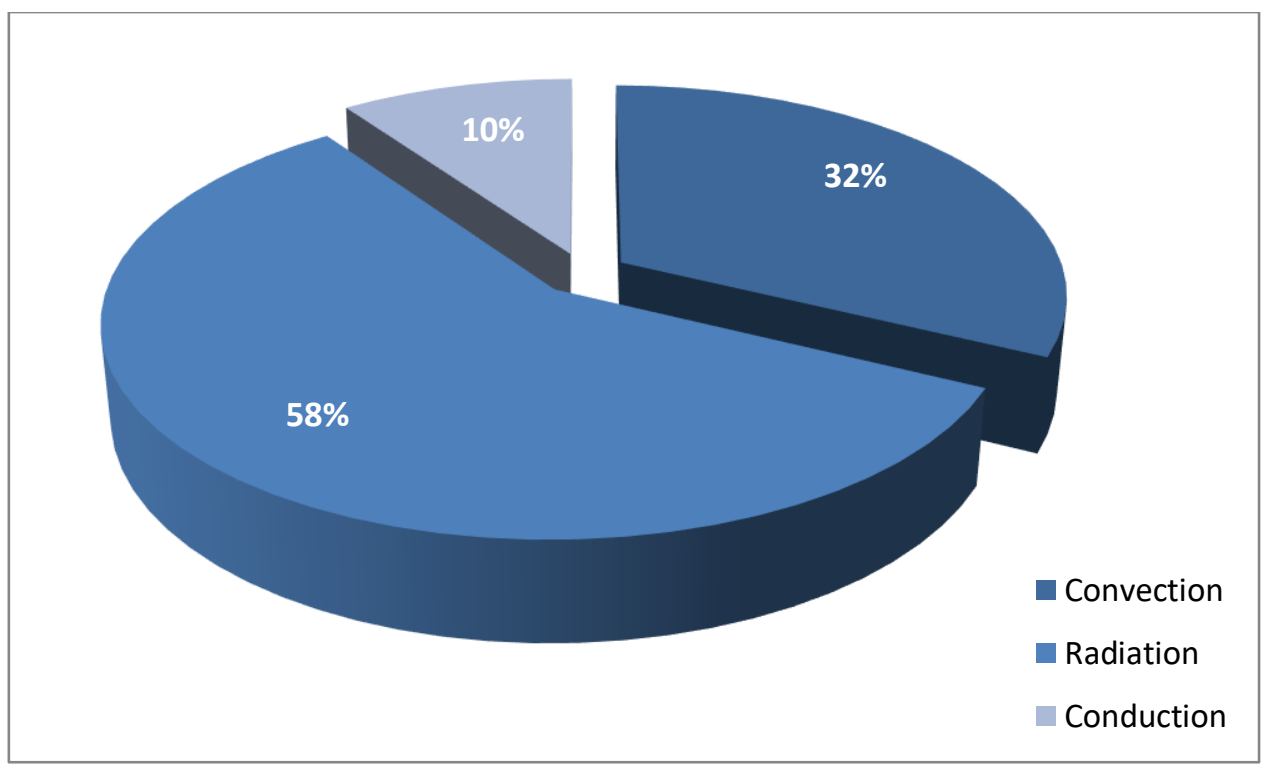

Figure 15. Energy lost by the different heat transfer mechanism during the whole day.

At last, the temperatures of the panels and the fluid inside the tubes forming the panels are plotted, Figure 16, the dashed lines represent the HTF temperature. The greatest difference between the fluid temperature 
and the surface temperature is $20^{\circ} \mathrm{C}$ for the coldest active panel and the lowest difference is $14{ }^{\circ} \mathrm{C}$ for the hottest active panel. From the Figure 16 it can be noted that it takes about 23 minutes for the temperature at the outlet to reach its steady state value.

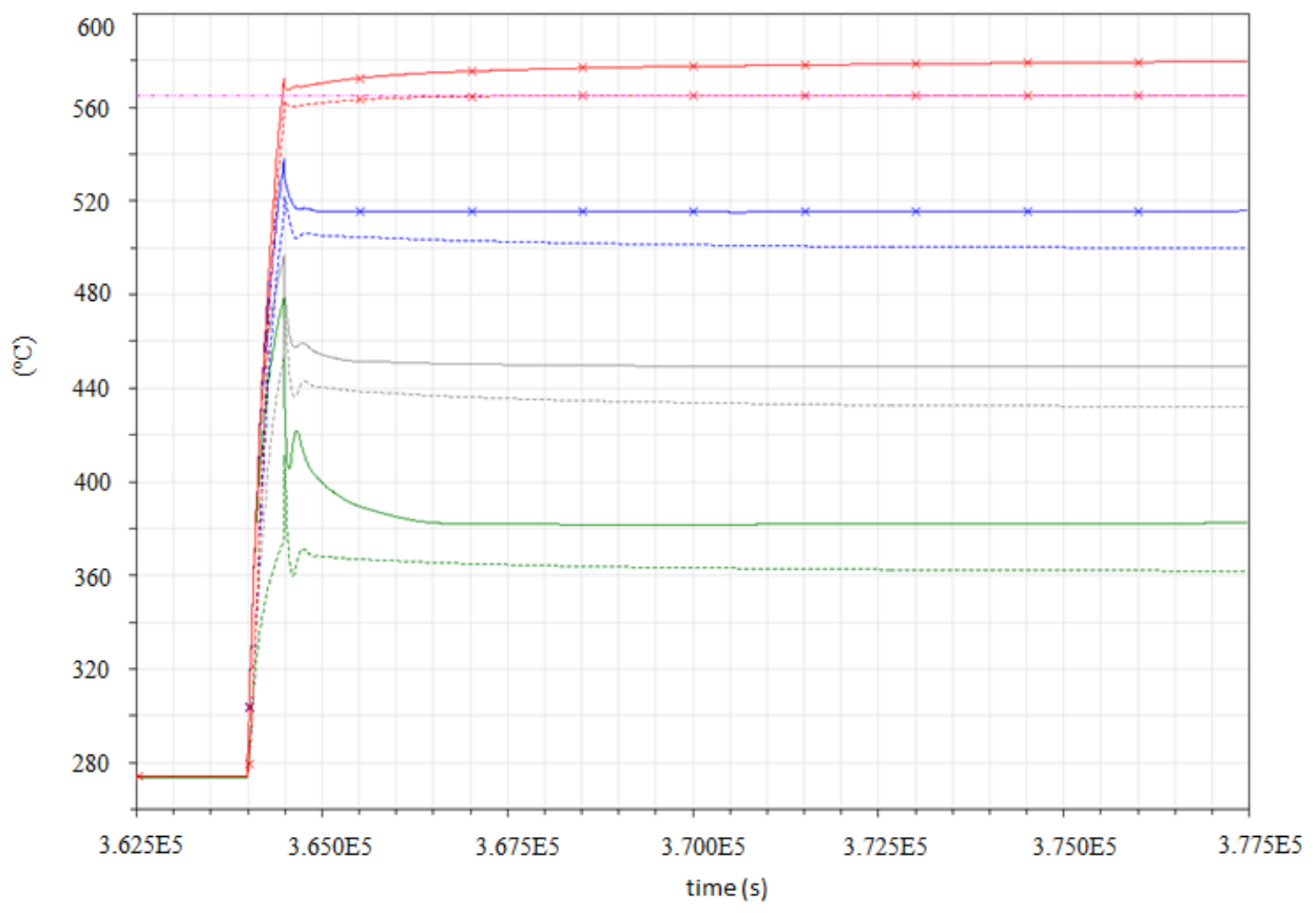

Figure 16. Temperature in the panels' surfaces, temperatures of the fluid inside each panel and cavity average temperature.

\subsubsection{Performance of the PI Adaptive Controller}

In the second set of simulations, the performance of the system controlled by the adaptive PI controller developed for the model is analyzed. This analysis is performed for 2 different days, the first one, simulation a), with high DNI and high disturbances (22/June/2008) and the second one, simulation b), with slow changes in the DNI forcing the receiver to work in different operation points (23/6/2008).

Figure 17 shows the results of the simulations for the three days. In the first image of each simulation the DNI, the set-point, the HTF outlet temperatures and the mass flow rates are represented, in the second one, the temperature response is analyzed and in the third one both mass flow rates are compared.

Simulation a) (high disturbances in the DNI) reveals how the pump is turned off when passing clouds cover the whole heliostat field. The mass flow is forced to be zero, and thus the temperature falls, raising again once the clouds are gone. Simulation b) reveals how the receiver is able to track the set-point temperature for the different operating points. 
a) $22 / 6 / 2008$
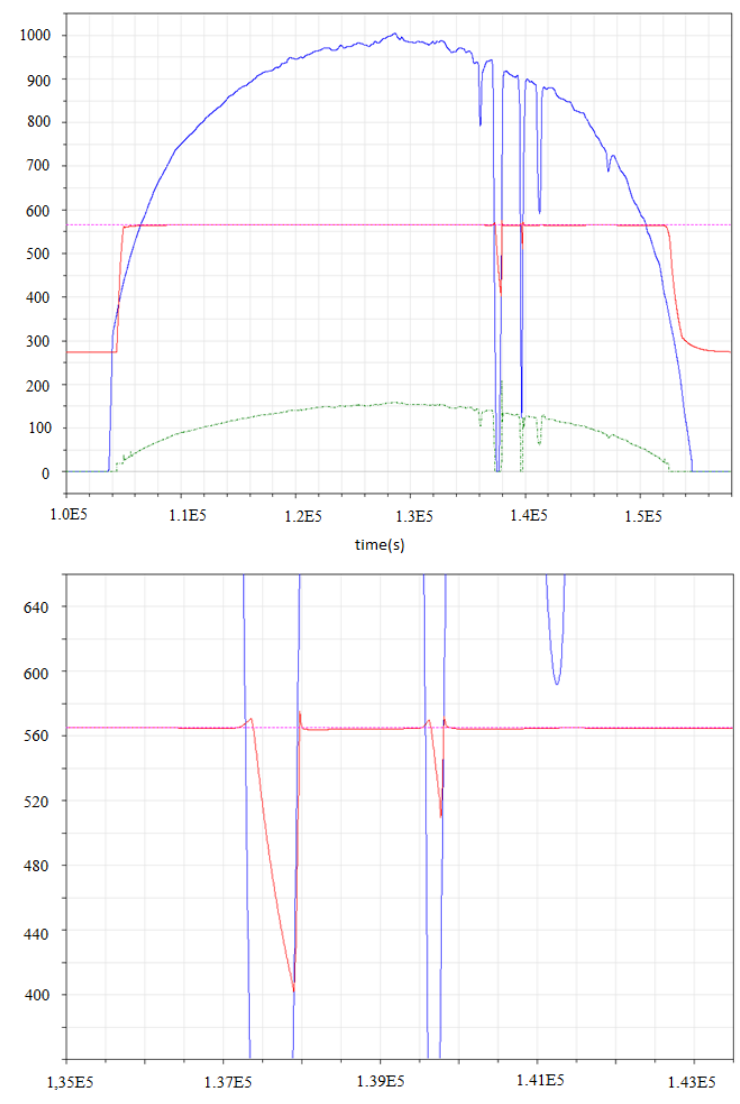

time(s)

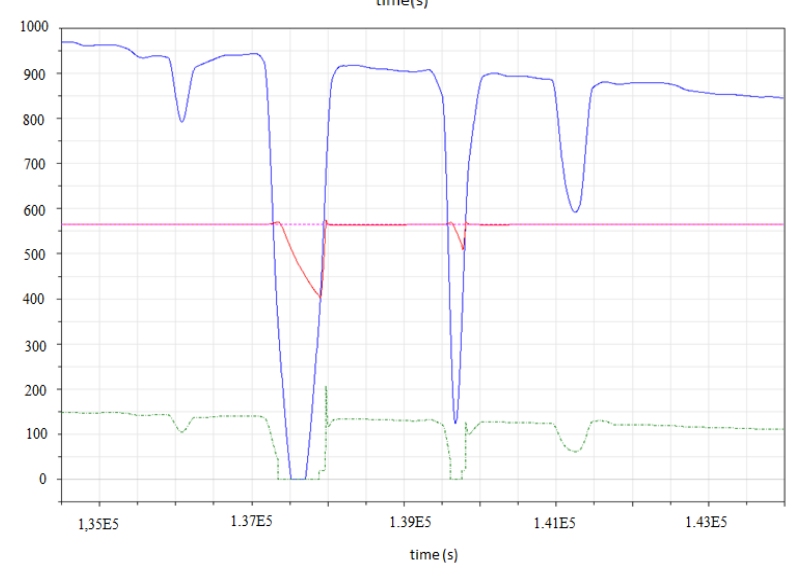

b) $23 / 6 / 2008$
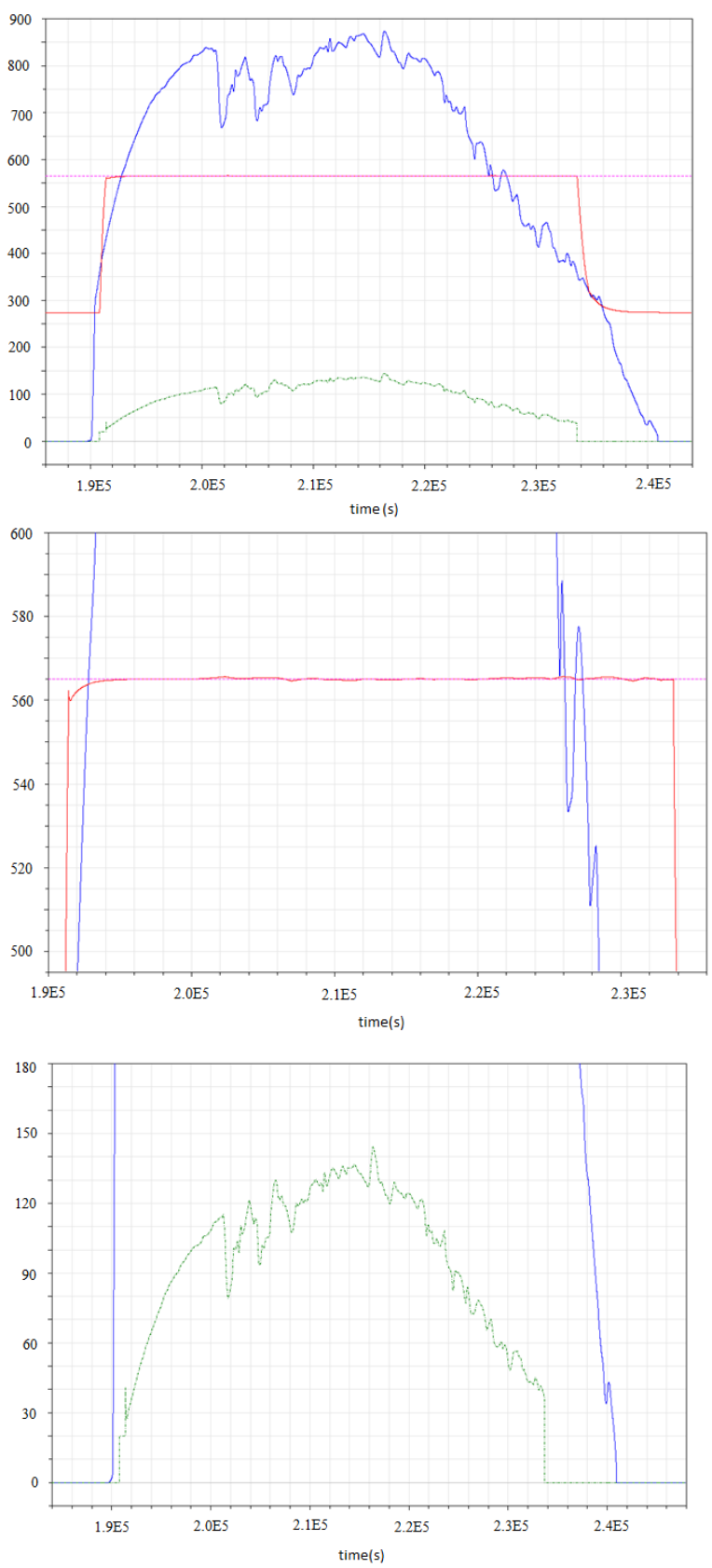

Figure 17. Graphs for the 2 different days of peration representing DNI (blue), set-point temperature(pink dashed), HTF outlet temperature (red line) and mass flow rate (green dasheddotted line).

\section{Conclusions}

This work presents a transient cavity receiver model, in which all the main heat transfer mechanisms, namely radiation, convection and conduction heat flows, are modeled in a detailed but still fast manner. Besides, it allows for certain flexibility in terms of the modeled geometry by adjusting the view factors for all the surfaces. It also includes an adaptive control able to predict the dynamic response of the receiver for different operating points. The model is based on the freely available Modelica standard library MSL. The implemented model has been used to simulate a PS10-like cavity receiver using molten salts as working fluid and evaluated through transient simulations. The model is subjected to changes in mass flow rate and 
changes in ambient conditions, proving that the developed controller achieves good performance for the different operating points.

The model is able to predict the transient performance of a cavity receiver over long periods of time for different configurations. The simulation performed proves the plausibility of the model and the convenience of implementing an adaptive controller able to be adapted through the operation of the receiver.

Future work should include the validation of the presented model through detailed simulation using CFD and/or through prototype testing. Also, further work is needed to evaluate and better adjust the coefficients used for the estimator of wind velocities inside the cavity.

Acknowledgements

The authors would like to thank the BSRN for maintaining and providing a comprehensive and reliable solar irradiation data base. Especially, the authors would like to thank the people involved at the station Desert Rock, Nevada, USA.

References

[1] F. B. I. Limited. CSP Today.

[2] S. H. Teichel, "Modeling and Calculation of Heat Transfer Relationships for Concentrated Solar Power Receivers," University of Wisconsin-Madison, vol. Master of Science, 2011.

[3] R. W. Bradshaw and R. W. Carling, "A review of the chemical and physical properties of molten alkali nitrate salts and their effect on materials used for solar central receivers," SAND-87-8005; Other: ON: DE88010500 United StatesOther: ON: DE88010500Fri Feb 08 07:05:01 EST 2008NTIS, PC A03/MF A01; 1.SNL; ERA-13-048415; EDB-88-154098English, 1987.

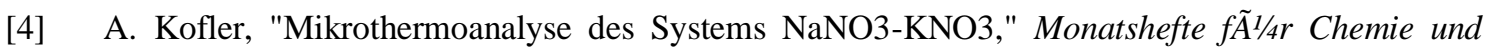
verwandte Teile anderer Wissenschaften, vol. 86, pp. 643-652, 1955.

[5] J. B. Fang, J. J. Wei, X. W. Dong, and Y. S. Wang, "Thermal performance simulation of a solar cavity receiver under windy conditions," Solar Energy, vol. 85, pp. 126-138, 2011.

[6] D. L. Siebers, J. S. Kraabel, L. Sandia National, and E. United States. Dept. of, Estimating Convective Energy Losses from Solar Central Receivers: Sandia National Laboratories for the U.S. Department of Energy, 1984.

[7] A. M. Clausing, "Convective Losses from Solar Central Receivers - Comparisons," Journal of Solar Energy Engineering, vol. Vol. 105, pp. 29-33, 1983.

[8] A. M. Clausing, J. M. Waldvogel, and L. D. Lister, "Natural Convection From Isothermal Cubical Cavities With a Variety of Side-Facing Apertures," Journal of Heat Transfer, vol. 109, pp. 407-412, 1987.

[9] U. Leibfried and J. Ortjohann, "Convective Heat Loss from Upward and Downward-Facing Cavity Solar Receivers: Measurements and Calculations," Journal of Solar Energy Engineering, vol. 117, pp. 75-84, 1995.

[10] S. Paitoonsurikarn and K. Lovegrove, "A new correlation for predicting the free convection loss from solar dish concentrating receivers," in Proceedings of 44th ANZSES conference, Australia, 2006, pp. 1-9.

[11] J. Samanes, J. García-Barberena, F. Zaversky, "Modeling solar cavity receivers: A review and comparison of natural convection heat loss correlations," 2014. 
[12] E. F. Camacho, F. R. Rubio, M. Berenguel, and L. Valenzuela, "A survey on control schemes for distributed solar collector fields. Part II: Advanced control approaches," Solar Energy, vol. 81, pp. 1252-1272, 2007.

[13] E. F. Camacho, F. R. Rubio, M. Berenguel, and L. Valenzuela, "A survey on control schemes for distributed solar collector fields. Part I: Modeling and basic control approaches," Solar Energy, vol. 81, pp. 1240-1251, 2007.

[14] SOLUCAR, "PS10: a 11.0-MWe Solar Tower Power Plant with Saturated Steam Receiver."

[15] H. Elmqvist and S. E. Mattsson, "Modelica - The next generation modeling language - An international design effort," presented at the Proceedings of the 1st World Congress on System Simulation, Singapore, 1997.

[16] Modelica-Association, "Modelica® - A Unified Object-Oriented Language for Systems Modeling Language Specification - Version 3.3," ed. https://www.modelica.org (accessed 14.11.2012): Modelica-Association, 2012.

[17] Dassault-Systèmes, "Dymola - Multi-Engineering Modeling and Simulation," ed. http://www.3ds.com (accessed 14.11.2012): Dassault-Systèmes, 2012.

[18] Open-Source-Modelica-Consortium, "OpenModelica - An open-source Modelica-based modeling and simulation environment," ed. http://www.openmodelica.org (accessed 8.1.2013): Open Source Modelica Consortium (OSMC), 2013.

[19] R. Franke, F. Casella, M. Sielemann, K. Proelss, M. Otter, and M. Wetter, "Standardization of Thermo-Fluid Modeling in Modelica.Fluid " presented at the Proceedings 7th Modelica Conference, Como, Italy, 2009.

[20] H. Tummescheit, "Design and Implementation of Object-Oriented Model Libraries using Modelica - PhD Thesis ", ed. Lund, Sweden: Department of Automatic Control - Lund Institute of Technology, 2002.

[21] F. Zaversky, M. Sanchez, and D. Astrain, "Object-oriented modeling for the transient response simulation of multi-pass shell-and-tube heat exchangers as applied in active indirect thermal energy storage systems for concentrated solar power," Energy, vol. 65, pp. 647-664, 2014.

[22] F. Zaversky, R. Medina, et al. "Object-oriented modeling for the transient performance simulation of parabolic trough collectors using molten salt as heat transfer fluid." Solar Energy 109(0): 93-94.

[23] V. Gnielinski, "Neue Gleichungen für den Wärme- und den Stoffübergang in turbulent durchströmten Rohren und Kanälen," Forschung im Ingenieurwesen A, vol. 41, pp. 8-16, 1975.

[24] L. F. Moody, "Friction factors for pipe flow," Transactions of the ASME, vol. 66, pp. 671-684, 1944.

[25] A. B. Zavoico, "Solar power tower design basis document," Sandia National Laboratories, vol. SAND 2001-2100, July 2001.

[26] R. Ferri, A. Cammi, and D. Mazzei, "Molten salt mixture properties in RELAP5 code for thermodynamic solar applications," International Journal of Thermal Sciences, vol. 47, pp. 1676$1687,2008$.

[27] B. a. Fromberg, "The Thermal Radiance of Clear Skies," Solar Energy, vol. 29, pp. 229-314, 1982.

[28] A. L. Buck, "New Equations for Computing Vapor Pressure and Enhancement Factor," Journal of Applied Meteorology, vol. 20, pp. 1527-1532, 2014/05/15 1981. 
[29] R. D. C. Team, "R: A language and environment for statistical computing. R Foundation for Statistical Computing, Vienna, Austria," 2008.

[30] V. Eric and J. G. Leonidas, "Optimally combining sampling techniques for Monte Carlo rendering," presented at the Proceedings of the 22nd annual conference on Computer graphics and interactive techniques, 1995.

[31] A. S. Glassner, An Introduction to Ray Tracing: Academic Press, 1989.

[32] C. Edzer Pebesma [aut], Roger Bivand [aut], Barry Rowlingson [ctb], Virgilio Gomez-Rubio [ctb], "sp: classes and methods for spatial data," 2013.

[33] H. C. K. Hottel, J.D.,, "Effect of reradiation on heat transmission in furnaces and through openings," ASME, vol. vol. 55, pp. pp. 39-49., 1933.

[34] J. R.Howell, "A Catalog of Radiation Heat Transfer Configuration Factors " 1982.

[35] F. Kreith, R. Manglik, and M. Bohn, Principles of Heat Transfer: Cengage Learning.

[36] A. M. Clausing, "An analysis of convective losses from cavity solar central receivers," Solar Energy, vol. 27, pp. 295-300, 1981.

[37] R. K. McMordie, "Convection heat loss from a cavity receiver," ASME Journal of Solar Energy Engineering, vol. Vol. 106, pp. 98-100., 1984.

[38] Y. A. Cengel, Heat \& Mass Transfer: A Practical Approach: McGraw-Hill Education (India) Pvt Limited, 2007.

[39] B. Y. H. Liu and R. C. Jordan, "The long-term average performance of flat-plate solar-energy collectors: With design data for the U.S., its outlying possessions and Canada," Solar Energy, vol. 7, pp. 53-74, 1963/6// 1963.

[40] E. Hairer, S. P. NÃssett, and G. Wanner, Solving Ordinary Differential Equations II: Stiff and Differential-Algebraic Problems: Springer, 1996.

[41] R. Pickhardt, Adaptive control of a solar power plant using a multi-model vol. 147, 2000.

[42] A. H. T. Åström K.J., "PID Controllers: Theory, Design, and Tuning," Instrument Society of America, vol. 2nd edition, 1995. 